\title{
The European forest sector: past and future carbon budget and fluxes under different management scenarios
}

\author{
Roberto Pilli ${ }^{1}$, Giacomo Grassi ${ }^{1}$, Werner A. Kurz ${ }^{2}$, Giulia Fiorese ${ }^{1}$, and Alessandro Cescatti ${ }^{1}$ \\ ${ }^{1}$ European Commission, Joint Research Centre, Directorate D - Sustainable Resources - Bio-Economy Unit, \\ Via E. Fermi 2749, I-21027 Ispra (VA), Italy \\ ${ }^{2}$ Natural Resources Canada, Canadian Forest Service, Victoria, BC, V8Z 1M5, Canada \\ Correspondence to: Roberto Pilli (roberto.pilli@ec.europa.eu)
}

Received: 5 December 2016 - Discussion started: 12 December 2016

Revised: 10 April 2017 - Accepted: 11 April 2017 - Published: 11 May 2017

\begin{abstract}
The comprehensive analysis of carbon stocks and fluxes of managed European forests is a prerequisite to quantify their role in biomass production and climate change mitigation. We applied the Carbon Budget Model (CBM) to 26 European countries, parameterized with country information on the historical forest age structure, management practices, harvest regimes and the main natural disturbances. We modeled the $\mathrm{C}$ stocks for the five forest pools plus harvested wood products (HWPs) and the fluxes among these pools from 2000 to 2030 . The aim is to quantify, using a consistent modeling framework for all 26 countries, the main $\mathrm{C}$ fluxes as affected by land-use changes, natural disturbances and forest management and to assess the impact of specific harvest and afforestation scenarios after 2012 on the mitigation potential of the EU forest sector. Substitution effects and the possible impacts of climate are not included in this analysis.

Results show that for the historical period from 2000 to 2012 the net primary productivity (NPP) of the forest pools at

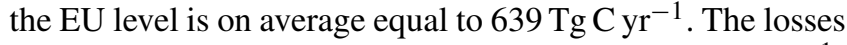

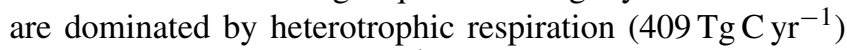

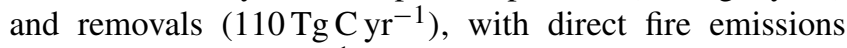
being only $1 \mathrm{TgC} \mathrm{yr}^{-1}$, leading to a net carbon stock

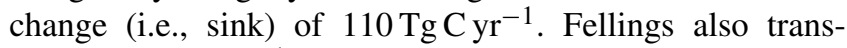
ferred $28 \mathrm{Tg} \mathrm{C} \mathrm{yr}^{-1}$ of harvest residues from biomass to dead organic matter pools. The average annual net sector exchange (NSE) of the forest system, i.e., the carbon stock changes in the forest pools including HWP, equals a sink of $122 \mathrm{TgC} \mathrm{yr}^{-1}$ (i.e., about $19 \%$ of the NPP) for the historical period, and in 2030 it reaches 126, 101 and $151 \mathrm{Tg} \mathrm{C} \mathrm{yr}^{-1}$, assuming constant, increasing (+20\%) and decreasing $(-20 \%)$ scenarios, respectively, of both harvest
\end{abstract}

and afforestation rates compared to the historical period. Under the constant harvest rate scenario, our findings show an incipient aging process of the forests existing in 1990: although NPP increases $(+7 \%)$, heterotrophic respiration increases at a greater rate $(+13 \%)$ and this leads to a decrease in the sink in the forest pools $(-6 \%)$ in 2030 compared to the historical period.

By comparing the evolution of the biomass as a function of the NPP (i.e., the turnover time) for each country, we highlighted at least three groups of countries and turnover times. This means that, contrary to the assumptions proposed by other authors, this relationship cannot be assumed as a constant for all the EU countries, but specific conditions, such as the harvest rate, the current age structure and the forest composition, may contribute to the country-specific evolution of biomass stocks.

The detailed picture of the $\mathrm{C}$ fluxes condensed in this study, and their evolution under different harvest scenarios, may represent both a benchmark for similar studies and a basis for broader analyses (e.g., including substitution effects of wood) on the mitigation potential of the EU forest sector.

\section{Introduction}

Forest management in Europe has a long tradition that has strongly influenced the present species composition (Spiecker, 2003), and it will continue to be the main driver affecting the productivity of European forests for the next decades (Koehl et al., 2010). A comprehensive assessment of the overall carbon stocks and fluxes of managed forests is 
required to complement the analyses of climate change impacts on forest productivity and composition (e.g., Lindner et al., 2015). Several studies analyzed the European forest carbon budget from different perspectives and over different time periods (Kauppi et al., 1992; Karjalainen et al., 2003), using different approaches, such as process-based ecosystem models (i.e., Valentini et al., 2000) or estimates based on forest inventories (i.e., Liski et al., 2000). Each of these methods has its strengths and weaknesses (Karjalainen et al., 2003).

Although several studies tried to harmonize different data sources (i.e., Böttcher et al., 2012) and link or compare the results from different approaches (i.e., Ťupek et al., 2010; Neumann et al., 2015), relevant differences still exist between the national reported values and the calculations from large-scale models (Groen et al., 2013). Atmospheric biogeochemical models focus on long-term physiological responses to climate change but are not suited for capturing the effect of different management practices (Karjalainen et al., 2003; Ťupek et al., 2010). For analyzing the impact of human activities on the current and near-future forest $\mathrm{C}$ stocks and fluxes, inventory-based models are the most appropriate tool. Furthermore, there are still knowledge gaps that should be addressed (Bellassen and Luyssaert, 2014), while also addressing more complex analyses, such as the challenges posed by increasing natural disturbances and other global changes (Trumbore et al., 2015).

In 2003, Karjalainen et al., using an inventory-based model (EFISCEN; Sallnäs, 1990) applied to data from national forest inventories (NFIs, mainly from the 1990s), quantified forest carbon fluxes at the country and European levels, looking both at the historical period 1990-2000 and at future management and climate scenarios, up to 2050. This analysis can now be updated thanks to the availability of new NFIs, further information from the UNFCCC country reports and data provided by other studies (i.e., Luyssaert et al., 2010; Schulze et al., 2010; Ťupek et al., 2010).

The aim of this study is to provide a comprehensive quantification of the carbon stocks and fluxes of the EU forest sector, including country-level details. We used an inventorybased model (Carbon Budget Model, CBM-CFS3; Kurz et al., 2009) and applied it to $26 \mathrm{EU}$ countries for the historical period 2000-2012 and for future scenarios of different harvest and afforestation rates (up to 2030).

In particular, we focus on the effects of forest age structure, natural disturbances, land-use change and management activities on (i) the amount of carbon stocked in the five forest $\mathrm{C}$ pools (i.e., above- and belowground biomass, dead wood, litter and soil) and outside the forest (i.e., harvested wood products, HWP). When possible, we further distinguish between merchantable biomass, branches, biomass used for energy, etc., and (ii) the fluxes, i.e., the inputs to and the outputs from each pool, and the exchanges between the forest sector and the atmosphere. Given the relatively short timeframe analyzed in our study (30 years), we do not consider the effects of climate change on forests. Other factors not covered by this study are substitution effects (Sathre and O'Connor, 2010; Smyth et al., 2016) and biophysical effects (Naudts et al., 2016; Alkama and Cescatti, 2016).

\section{Material and methods}

\subsection{The Carbon Budget Model (CBM-CFS3) and NFI input data}

The CBM is an inventory-based, yield-curve-driven model that simulates the stand- and landscape-level $\mathrm{C}$ dynamics of above- and belowground biomass, dead organic matter (DOM; litter and dead wood) and mineral soil (Kurz et al., 2009). The model, developed by the Canadian Forest Service, was recently applied to $26 \mathrm{EU}$ countries, mainly using NFI input data (Table 1), to estimate the EU forest C dynamics from 2000 to 2012, including the effects of natural disturbances and land-use change (Pilli et al., 2016a, b). Here we apply the same methods, data and assumptions as these studies, with the exception of Bulgaria, Ireland, Poland and Romania, where we updated our input data (see Table 1 for details). We refer the reader to Kurz et al. (2009) for details on the model and to Pilli et al. (2016a, c) for details on its application to EU countries.

The spatial framework applied in the CBM conceptually follows IPCC reporting method 1 (Penman et al., 2003), in which the spatial units are defined by their geographic boundaries and all forest stands are geographically referenced to a spatial unit (SPU). Within a SPU, each forest stand is characterized by age, area and seven classifiers that provide administrative and ecological information: the link to the appropriate yield curves; the parameters defining the silvicultural system, such as the forest composition (defined according to different forest types, FTs); the management type (MT); and the main use of the harvest provided by each SPU (fuelwood or industrial roundwood). From the NFIs of each country, we derived (i) the original age-class distribution (for the even-aged forests), (ii) the main FTs based on the forest composition (each FT was assumed to be composed of the main species reported in the NFI, i.e., it was assumed as a pure FT), (iii) the average volume and current annual increment (if possible, defined for each FT) and (iv) the main MTs. These last parameters may include evenaged high forests, uneven-aged high forests, coppices and specific silvicultural systems such as clear cuts (with different rotation lengths for each FT), thinnings, shelterwood systems, partial cuttings, etc. In a few cases, because of the lack of country-specific information, some of these parameters were derived either from the literature or from average values reported for other countries.

In the CBM, species-specific, stand-level equations (Boudewyn et al., 2007) convert merchantable volume per hectare into aboveground biomass, partitioned into merchantable stem wood, other (tops, branches, sub- 
Table 1. Main parameters applied in the Carbon Budget Model (CBM). Detailed information can be found in Pilli et al. (2016a), with the exception of Bulgaria, Ireland, Poland and Romania (see the table's notes). The table reports the National Forest Inventory (NFI) original reference year; the starting year of model application, the base forest management area (FM, i.e., area of the existing forests in 1990), the additional natural disturbance events considered in the model (F, fire; S, storms and ice sleets; and I, insect attacks).

\begin{tabular}{|c|c|c|c|c|}
\hline COUNTRY & $\begin{array}{l}\text { Original NFI } \\
\text { year }\end{array}$ & $\begin{array}{l}\text { Time step } \\
0(\mathrm{yr})\end{array}$ & $\begin{array}{r}\text { CBM FM } \\
\text { area }(\mathrm{Mha})^{2}\end{array}$ & $\begin{array}{l}\text { Natural } \\
\text { disturbances }\end{array}$ \\
\hline Austria & 2008 & 1998 & 3.2 & $\mathrm{~S}+\mathrm{I}$ \\
\hline Belgium & 1999 & 1999 & 0.7 & - \\
\hline Bulgaria $^{3}$ & 2010 & 2000 & 3.6 & $S$ \\
\hline Croatia & $2006^{1}$ & 1996 & 2.0 & $\mathrm{~F}$ \\
\hline Czech Republic & 2000 & 2000 & 2.6 & - \\
\hline Denmark & 2004 & 1994 & 0.5 & S \\
\hline Estonia & 2000 & 2000 & 2.1 & S \\
\hline Finland & 1999 & 1999 & 21.7 & S \\
\hline France & 2008 & 1998 & 14.6 & $S$ \\
\hline Germany & 2002 & 1992 & 10.6 & S \\
\hline Greece & $1992^{1}$ & 1992 & 1.2 & $\mathrm{~F}$ \\
\hline Hungary & 2008 & 1998 & 1.6 & - \\
\hline Ireland $^{3}$ & 2005 & 1995 & 0.5 & $\mathrm{~F}$ \\
\hline Italy & 2005 & 1995 & 7.4 & $\mathrm{~F}$ \\
\hline Latvia & 2009 & 1999 & 3.2 & $\mathrm{~S}$ \\
\hline Lithuania & 2006 & 1996 & 2.0 & $\mathrm{~S}+\mathrm{F}+\mathrm{I}$ \\
\hline Luxembourg & 1999 & 1999 & 0.1 & $\mathrm{~S}$ \\
\hline Netherlands & 1997 & 1997 & 0.3 & S \\
\hline Poland ${ }^{4}$ & 2010 & 2000 & 9.1 & S \\
\hline Portugal & 2005 & 1995 & 3.6 & $\mathrm{~F}$ \\
\hline Romania $^{3}$ & 2010 & 1990 & 6.3 & - \\
\hline Slovakia & 2000 & 2000 & 1.9 & $\mathrm{~S}+\mathrm{F}$ \\
\hline Slovenia & 2000 & 2000 & 1.1 & $\mathrm{~S}+\mathrm{F}$ \\
\hline Spain & 2002 & 1992 & 12.6 & $\mathrm{~F}$ \\
\hline Sweden & 2006 & 1996 & 22.6 & $\mathrm{~S}$ \\
\hline United Kingdom & 1997 & 1997 & 2.5 & $S+F$ \\
\hline EU & & & 138.0 & 22 countries \\
\hline
\end{tabular}

\footnotetext{
1 Analysis based on data from forest management plans. ${ }^{2}$ FM area used by CBM at time step 0 (see Pilli et al., 2016a for further details). ${ }^{3}$ New NFI input data (directly provided by the countries) and methodological assumptions (see Pilli et al., 2016c for details) were applied for Bulgaria, Ireland and Romania, as compared to Pilli et al. (2016b). ${ }^{4}$ New NFI input data, reported by the second NFI cycle (2010-2014, Bureau for Forest Management and Geodesy, 2015) were used for Poland, as compared to Pilli et al. (2016b)
}

merchantable size trees) and foliage components. Where additional information provided by NFIs or literature was available, country-specific equations were selected to convert the merchantable volume into aboveground biomass (Pilli et al., 2013).

We used two sets of yield tables in these analyses (Pilli et al., 2013, 2016a). Historical yield tables, derived from the standing volumes per age class reported by the NFI, represent the impacts of growth and partial disturbances during stand development. Current yield tables, derived from the current annual increment reported in country NFIs, represent the stand-level volume accumulation in the absence of natural disturbances and management practices.

For 22 countries, we also evaluated the impact of natural disturbance events, including storms and ice, fires, and bark beetle attacks (Table 1). Specific information on the assumptions on natural disturbances can be found in Pilli et al. (2016a, c).

The CBM uses biomass turnover rates to represent mortality of biomass and litterfall rates and the transfer of dead biomass to DOM pools (Kurz et al., 2009). Due to the lack of studies, in many cases we could not define these parameters at the regional level. The decomposition rate for each DOM pool, however, is modeled using a temperature-dependent decay rate that determines the amount of organic matter that decomposes each year. For this reason, maps of temperature and precipitation classes were projected over a CORINE map and over the European administrative units, following the approach of Pilli (2012). The resulting combinations of precipitation and mean temperature values were used to define 
60 climatic land units (CLUs; as in Pilli, 2012) and, for each country, a portion of the NFI forest area was associated with each CLU, on the basis of CORINE data.

The model provides annual estimates of $\mathrm{C}$ stocks and fluxes, such as the annual $\mathrm{C}$ transfers between pools, from pools to the atmosphere and from pools to the forest product sector, as well as ecological indicators such as the net primary production (NPP), heterotrophic respiration $\left(R_{\mathrm{h}}\right)$ or net biome production (NBP). Afforestation (AR) and deforestation can be represented as disturbance types with their own disturbance matrices and transitions to and from forest land.

In order to model land-use changes (i.e., afforestation and deforestation), we need to define a benchmark (i.e., a baseline) for the forest area existing in a given year. To be consistent with other studies and to provide more useful information (at the country level), we use 1990 as the base year, which is also the Kyoto Protocol base year (details in Pilli et al., 2016a). For simulations that started after 1990, this area was decreased to account for the total amount of deforestation reported by each country (KP CRF tables, 2014) between 1990 and time step 0, i.e., the beginning of the model run (which varies by country, as reported in Table 1).

If the NFI reference year was after 2000, we rolled back the original NFI age-class distribution (for even-aged forests) in the inventory (Pilli et al., 2013, 2016a) by 10 years to provide a consistent dataset covering the period 2000-2012 for all EU countries.

We considered the historical effect (i.e., up to 2012, depending on the available data) of the main storms and ice damages (16 countries), fires (10 countries), and insect attacks (i.e., bark beetle attacks for two countries; see Table 1 and Pilli et al., 2016a).

AR was modeled through country-specific model runs, always beginning in 1990, applying the historical annual rate of AR reported by each country up to 2012 (Pilli et al., 2016b). The total amount of AR per year was distributed between different FTs, according to the proportional amount of the forest management (FM) area.

\subsection{Harvest demand and carbon flow}

The main fluxes modeled in our study are (1) inputs of C from the atmosphere (i.e., NPP) to the forest ecosystem; (2) outputs due to direct $\mathrm{C}$ emissions from the forest to the atmosphere and due to harvest activities; and (3) internal fluxes (not affecting the total $\mathrm{C}$ balance), mainly from the living biomass to the DOM pool (see also Fig. S1 in the Supplement for more details). Carbon enters the forest as $\mathrm{CO}_{2}$ absorbed from the atmosphere by living biomass (LB); a fraction of this biomass returns to the atmosphere (through natural disturbances such as fires and storms) or moves to the other forest pools (dead wood and litter) through natural mortality and disturbance events. From these pools, $\mathrm{C}$ can be directly released to the atmosphere or transferred to the soil pool where some of it can reside for centuries. All these ecosystem car- bon fluxes are modeled in CBM with a semi-empirical approach (Kurz et al., 2009).

From an ecosystem perspective (Kirschbaum et al., 2001), the sum of all biomass production during 1 year represents the NPP, equal to the difference between the carbon assimilated by plants through photosynthesis (i.e., the gross primary production, GPP) and the carbon released by plants through autotrophic respiration $\left(R_{\mathrm{a}}\right)$ :

$\mathrm{NPP}=\mathrm{GPP}-R_{\mathrm{a}}$.

Subtracting from this figure all the $\mathrm{C}$ losses due to the heterotrophic respiration $\left(R_{\mathrm{h}}\right.$; i.e., decomposition), we estimate net ecosystem productivity (NEP):

$\mathrm{NEP}=\mathrm{NPP}-R_{\mathrm{h}}$.

NBP is the difference between NEP and the direct losses due to harvest $(\mathrm{H})$ and natural disturbances (D; e.g., fires):

$\mathrm{NBP}=\mathrm{NEP}-\mathrm{H}-\mathrm{D}$.

Through the fellings, a fraction of the LB moves to the HWP pool (this is the amount of biomass removed from the forest, i.e., the roundwood removals reported in Fig. S1). Another fraction of biomass is left in the forest as forest residues (i.e., slash, varying according to the specific silvicultural treatments). Fellings can also salvage a fraction of the standing dead trees and move them from the dead wood pool to the roundwood pool. Adding to the NBP the total changes in the HWP carbon stock $\left(\mathrm{HWP}_{\Delta \mathrm{C}}\right)$, we estimate the net sector exchange (NSE; Karjalainen et al., 2003):

$\mathrm{NSE}=\mathrm{NBP}+\mathrm{HWP}_{\Delta \mathrm{C}}$.

In this study, we applied the CBM as a timber assessment model, i.e., we defined a certain harvest level and implemented the model to (i) check if it is possible to harvest that amount and (ii) to simulate the forest development under that harvest level (Schelhaas et al., 2007). The total fellings were inferred, for each country, from the amount of roundwood removals reported by FAOSTAT data (FAOSTAT, 2013), further distinguishing between industrial roundwood (IRW; used for the production of wood commodities and mainly provided by stems) and fuelwood (FW; i.e., the wood for energy use, mainly provided by residues, branches and coppices). To provide a consistent estimate of the harvest demand for all the countries, these data were compared and, when needed, corrected with other information from the literature (i.e., to account for the bark fraction or other possible recognized biases; Pilli et al., 2015).

The 26 EU countries' total past and three alternative future harvest demands considered in this study are shown in Fig. 1. For each country, the total harvest, further distinguished between four compartments, provides the total amount of wood expected each year: IRW conifers, IRW broadleaves, FW 


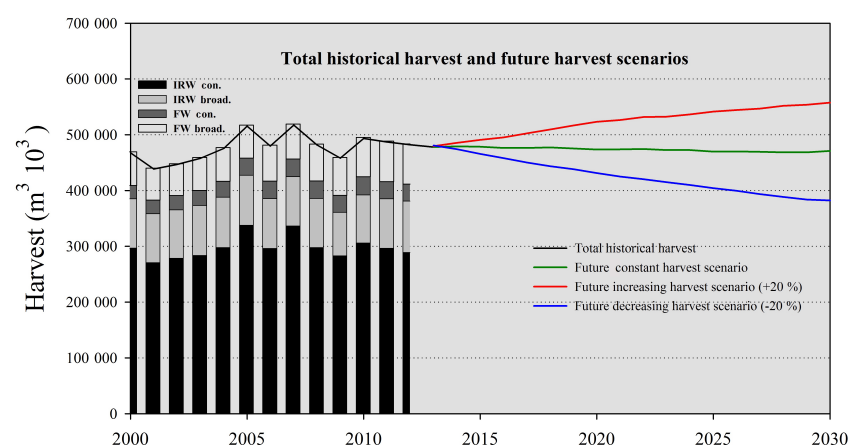

Figure 1. Total harvest demand for EU26 $\left(\mathrm{m}^{3} 10^{3}\right)$ for the historical period (2000-2012) and for three future scenarios (20132030), assuming average constant harvest, increasing harvest demand (i.e., $+20 \%$ in 2030) and decreasing harvest demand (i.e., $-20 \%$ in 2030). For the historical period, bars show the share of harvest distinguished between industrial roundwood (IRW) and fuelwood (FW) and conifers (con) and broadleaves (broad). The same ratios, corrected in proportion to the total harvest demand, were applied to each future harvest scenario.

conifers and FW broadleaves. For each compartment we defined (i) the FTs (i.e., broadleaved species for IRW and FW and coniferous species for IRW and FW), (ii) the MTs (for example coppices for FW broadleaves) and (iii) the silvicultural practices (for example thinnings for FW conifers). Original values of harvest demand expressed in cubic meters were converted to tons of $\mathrm{C}$ using species-specific wood density values and a constant $\mathrm{C}$ fraction equal to 0.50 (Penman et al., 2003). A further distribution between FTs and MTs associated with the same compartment was based on the total stock of aboveground biomass available at the beginning of the model run. The $\mathrm{C}$ annually stocked as harvested wood products (i.e., IRW) was directly derived by the estimates provided by Pilli et al. (2015), based on the same input data used in this study.

During the model run, we also quantified the amount of FW provided by branches and other wood components such as the amount of residues moved from the LB to the dead wood pool (see Fig. S1). A fraction of the LB due to deforestation could also be used as FW or IRW, but due to the lack of detailed information on this potential use, this amount was not included in the sum of the total roundwood removals; instead it was assumed as direct emission of $\mathrm{C}$ to the atmosphere.

Three harvest scenarios were explored from 2013 onward (combined with the FM area and the deforestation activities): (i) a constant harvest scenario based on the average historical harvest (2000-2012) up to 2030; (ii) an increasing harvest scenario, based on a $20 \%$ increase in the 2030 constant harvest demand and a linear interpolation between 2013 and 2030; and (iii) a decreasing harvest scenario, based on a $20 \%$ decrease to the 2030 constant harvest demand and a linear interpolation between 2013 and 2030 (Fig. 1). For each fu- ture harvest scenario, we distributed the total harvest demand between the four compartments (i.e., IRW and FW, con and broad), assuming the same proportions as in the historical period, i.e, about $62 \%$ of the total harvest was used as IRW coming from coniferous species, $19 \%$ was used as IRW coming from broadleaved species, $6 \%$ was used as FW coming from coniferous species and $13 \%$ was used as FW coming from broadleaved species.

We assumed that the harvest demand was entirely provided by the FM area, excluding potential harvest from deforestation. For AR we estimated the maximum potential (and theoretical) harvest from afforested areas, assuming a common set of silvicultural practices for all countries, with a single $15 \%$ commercial thinning applied to broadleaved forests that are 15 years or older and a single $20 \%$ commercial thinning applied to coniferous forests that are 20 years or older (Pilli et al., 2014b).

Table 2 summarizes all the assumptions concerning (i) the forest area, assumed as constant FM area minus the annual rate of deforestation; (ii) the effect of natural disturbances, concentrated in the FM area; and (iii) the harvest demand, based on FAOSTAT statistics and concentrated in the FM area. After 2012, we applied a constant average annual rate of deforestation to the FM area, combined with three different harvest scenarios (i.e., constant average, +20 and $-20 \%$ ); for $\mathrm{AR}$, we considered three different annual rates of AR (i.e., constant average, +20 and $-20 \%$ ), and we estimated for each scenario the maximum theoretical amount of harvest potentially provided by the AR area, assuming constant silvicultural practices.

\section{Results and discussion}

\subsection{Carbon balance at EU level}

The average total $\mathrm{C}$ stock estimated for the $26 \mathrm{EU}$ countries for the main FM pools is equal to $9417 \mathrm{Tg} \mathrm{C}$ for the living biomass; $1536 \mathrm{Tg} \mathrm{C}$ for dead wood; 1179 and $7717 \mathrm{Tg} \mathrm{C}$ for litter and soil (to a depth of $1 \mathrm{~m}$ ); and $1843 \mathrm{Tg} \mathrm{C}$ as the average amount of $\mathrm{C}$ in the HWP pool during the same period (based on the analysis provided by Pilli et al., 2015).

Figure 2 reports the historical (2000-2012) C fluxes modeled by CBM at the EU level, for the forest area existing in 1990 (i.e., the FM area) and for the HWP pool. Additional data for each $\mathrm{C}$ pool and flux and for the area afforested from 1990 to 2012 (AR) are reported in Fig. S1 and Table S1 in the Supplement. Living biomass and felling (i.e., the $\mathrm{C}$ contained in all removed harvested wood products, plus harvest primary residues) have a positive net $\mathrm{C}$ balance. We estimated a negative balance for dead wood and litter, probably influenced by the effects of natural disturbances, which have increased during the last decades (Seidl et al., 2014). Although our results focus on the historical period 2000-2012, for 20 out of 26 countries our model's simulations started be- 
Table 2. Assumptions and main parameters for the model scenarios. FM: forest management area, i.e., area of the existing forests in 1990. AR: afforestation and reforestation that has occurred since 1990).

\begin{tabular}{|c|c|c|c|c|}
\hline SCENARIOS & Area & $\begin{array}{l}\text { Natural distur- } \\
\text { bances }\end{array}$ & Harvest & Deforestation \\
\hline Constant harvest & $\begin{array}{l}\text { Constant FM area - } \\
\text { deforestation }\end{array}$ & $\begin{array}{l}\text { Yes, if relevant, } \\
\text { from } 2000 \text { to } \\
2011+\text { average } \\
\text { constant fire from } \\
2013 \text { to } 2030\end{array}$ & $\begin{array}{l}\text { Historical + constant } \\
\text { from } 2013\end{array}$ & $\begin{array}{l}\text { Yes, historical }+ \\
\text { constant since } 2013\end{array}$ \\
\hline Harvest $+20 \%$ & & & $\begin{array}{l}\text { Historical }+ \text { increasing } \\
\text { to }+20 \% \text { in } 2030\end{array}$ & \\
\hline Harvest $-20 \%$ & & & $\begin{array}{l}\text { Historical }+ \text { decreasing } \\
\text { to }-20 \% \text { in } 2030\end{array}$ & \\
\hline Constant AR & $\begin{array}{l}\text { Historical AR rate since } \\
1990+\text { constant average } \\
\text { AR rate } 2013-2030\end{array}$ & No & $\begin{array}{l}\text { Maximum theoretical } \\
\text { amount of harvest pro- } \\
\text { vided by AR, with con- } \\
\text { stant management prac- } \\
\text { tices }\end{array}$ & No \\
\hline $\mathrm{AR}+20 \%$ & $\begin{array}{l}\text { Historical AR rate since } \\
1990+\text { increasing to } \\
+20 \% \text { in } 2030\end{array}$ & & & \\
\hline $\mathrm{AR}-20 \%$ & $\begin{array}{l}\text { Historical AR rate since } \\
1990+\text { decreasing to } \\
-20 \% \text { in } 2030\end{array}$ & & & \\
\hline
\end{tabular}

fore 2000 (depending on the NFI reference year, as reported in Table 1). Therefore, the DOM C balance implicitly considers the effect of natural disturbances that occurred over a longer period, including the main storms affecting central and northern European countries in 1999 and 2005 and the large wildfires that occurred in 2007 in the Mediterranean countries. From 2000 to 2012, we estimated that, on average, $8 \mathrm{Tg} \mathrm{C} \mathrm{yr}^{-1}$ was moved from the living biomass to DOM due to natural disturbances, and, apart from direct $\mathrm{CO}_{2}$ emissions due to wildfires (about $1 \mathrm{TgC}^{-1}$ ), these processes also increased the indirect emissions due to heterotrophic decomposition of biomass killed by fire (Ghimire et al., 2012). Due to the short timeframe considered in our study, we could not identify any significant variation in the soil $\mathrm{C}$ stock. The slightly negative $\mathrm{C}$ stock change reported for this pool

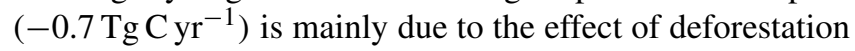
that moves forested lands to other land-use categories (i.e., as reported in Fig. 2, it is not a soil C loss to the atmosphere but a $\mathrm{C}$ transfer to other land-use categories). Overall, the soil C stock is stable.

The estimated average NPP is equal to $620 \mathrm{Tg} \mathrm{C} \mathrm{yr}^{-1}$ for the FM area (including the effect of deforestation that has oc-

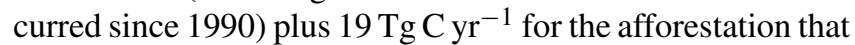
occurred since 1990. The total heterotrophic respiration $\left(R_{\mathrm{h}}\right)$ amounts to $403 \mathrm{TgC}^{-1}$, mainly due to the decay of the

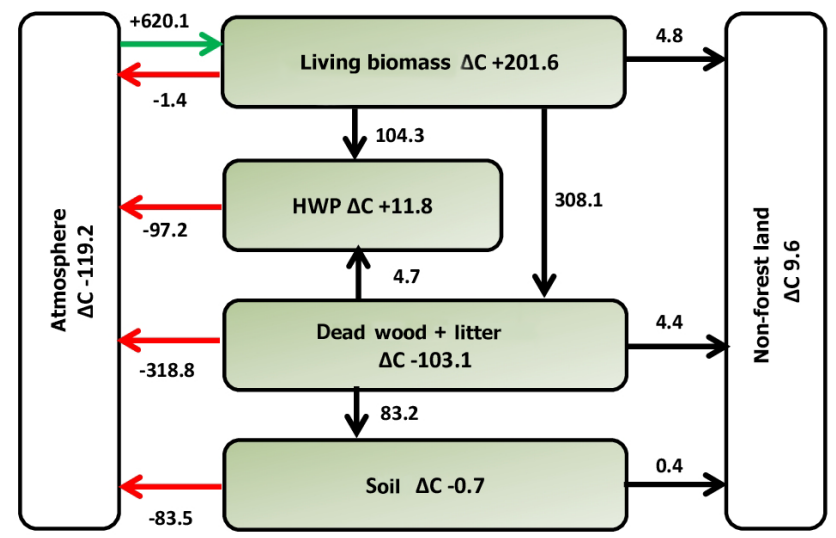

Figure 2. Summary of the average $\mathrm{C}$ increment and transfers between forest pools and with the atmosphere and non-forest land for the FM area (in teragrams of carbon per year, for the historical period 2000-2012). The pool increments are shown in each box as $\Delta \mathrm{C}$. Transfers between pools are shown as black arrows and transfers from and to the atmosphere are shown as green and red arrows, respectively (with positive or negative values, reported from a forest perspective). Further details are reported in Fig. S1. 


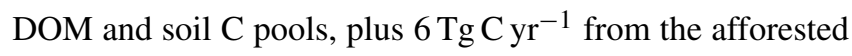
area.

The direct $\mathrm{C}$ emissions related to fire disturbances amount to about $1 \mathrm{Tg} \mathrm{C} \mathrm{yr}^{-1}$ (see Fig. S1 for details) and are consistent with the emissions reported by the countries to the UNFCCC (KP CRF Tables, 2014; see Pilli et al., 2016b, c, for further details). Other losses from biomass pools are related to fellings (about $138 \mathrm{Tg} \mathrm{Cyr}^{-1}$ ) and can be distinguished between wood removals (110 $\left.\mathrm{Tg} \mathrm{Cyr}^{-1}\right)$ and transfers of biomass residues to DOM pools ( $\left.28 \mathrm{Tg} \mathrm{C} \mathrm{yr}^{-1}\right)$, which decay over time (see Fig. S1). A consistent fraction (about 20\%) of the fellings are used as fuelwood and thus its $\mathrm{C}$ content is directly released to the atmosphere (see Fig. S1 and Table S1). As suggested by the 2013 IPCC KP LULUCF supplement, we assumed the instantaneous oxidation of the amount of harvest used as FW (Hiraishi et al., 2014). The remaining industrial roundwood component can be further distinguished between the $\mathrm{C}$ annually stocked as harvested wood products (12 $\mathrm{Tg} \mathrm{C} \mathrm{yr}^{-1}$ based on Pilli et al., 2015) and the $\mathrm{C}$ released

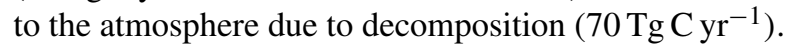

We compare our results with figures from the literature (Table 3). Luyssaert et al. (2010) analyzed the results of different methodologies for 25 EU countries during 1990-2005 and estimated an average annual NPP lower than our estimates $\left(520 \pm 75 \mathrm{Tg} \mathrm{C} \mathrm{yr}^{-1}\right)$. Karjalainen et al. (2003) estimated an average NPP equal to $409 \mathrm{Tg} \mathrm{C} \mathrm{yr}^{-1}$ for $27 \mathrm{EU}$ countries during 1995-2000. The average $R_{\mathrm{h}}$ estimated with

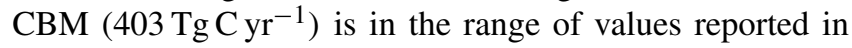
Luyssaert et al. (2010), but it is $40 \%$ higher than the figure in Karjalainen et al. (2003), probably because of the higher fine turnover rates used in CBM than those used in the Karjalainen et al. (2003) study. However, if we compare the relative emissions due to $R_{\mathrm{h}}$ with the total NPP, the estimates are not so different: $59 \%$ of the NPP is lost as heterotrophic respiration according to Karjalainen et al. (2009), and $65 \%$ is lost according to our study. The total emissions from harvested wood products reported by Luyssaert et al. (2010), equal to $87 \pm 16 \mathrm{Tg} \mathrm{C} \mathrm{yr}^{-1}$, are similar to our estimate. However, applying the IPCC Tier 2 method (Hiraishi et al., 2014; Pilli et al., 2015) we estimated a larger C sink for the HWP

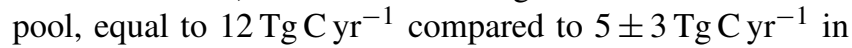
Luyssaert et al. (2010). The net emissions from HWP estimated in our study at the country and EU levels are consistent with the historical (i.e., until 2009) net emissions reported by Rüter (2011), using a similar modeling approach.

Finally, if we scale our estimates to units of area (see Table S2), results for NPP and harvest (4.5 $\mathrm{MgC} \mathrm{ha}^{-1} \mathrm{yr}^{-1}$ and $0.8 \mathrm{MgCha}^{-1}$ ) are similar to the estimates presented by Schulze et al. (2010) in a study based on a network of eddy covariance sites across Europe: $5.2 \pm 0.7$ and $0.6 \pm 0.1 \mathrm{MgC} \mathrm{ha}^{-1}$, for NPP and harvest, respectively.

Taking into account all these fluxes, we estimated a total NBP equal to 98 and $12 \mathrm{Tg} \mathrm{Cyr}^{-1}$ for the FM area and the afforested area (146 M ha in total), respectively. Adding the $\mathrm{C}$ stock increases in the HWP pool to these
NBP estimates, we estimate a NSE for the total forest sector of $122 \mathrm{Tg} \mathrm{Cyr}^{-1}$. Luyssaert et al. (2010) reported a NBP value of $109 \pm 30 \mathrm{Tg} \mathrm{C} \mathrm{yr}^{-1}$ that is similar to our estimate of $110 \mathrm{Tg} \mathrm{C} \mathrm{yr}^{-1}$ for the FM area.

The NPP of the FM area in 2030 increases from $620 \mathrm{Tg} \mathrm{Cyr}^{-1}$ (average 2000-2012) to $661 \mathrm{Tg} \mathrm{C} \mathrm{yr}^{-1}$ (i.e., $+6 \%), 653 \mathrm{Tg} \mathrm{Cyr}^{-1}(+5 \%)$ and $669 \mathrm{Tg} \mathrm{Cyr}^{-1}$ (+8\%), assuming constant, increasing and decreasing harvest scenarios, respectively (Fig. 3). In 2030, the area of lands that has been afforested since 1990 contributes about $39{\mathrm{Tg} \mathrm{C} \mathrm{yr}^{-1}}^{-1}$ more to the NPP than the average of the period 1990 to 2012, and NBP increases from $12 \mathrm{Tg} \mathrm{C} \mathrm{yr}^{-1}$ (average 20002012) to about $26 \mathrm{Tg} \mathrm{C} \mathrm{yr}^{-1}$ in 2030 for all the AR scenarios. As expected, in 2030, the decreasing harvest scenario (combined with a decreasing AR rate) has the highest total $\mathrm{NBP}\left(\mathrm{FM}+\mathrm{AR}\right.$ ), equal to $151 \mathrm{Tg} \mathrm{C} \mathrm{yr}^{-1}$ (see carbon sink in Fig. 3).

The natural turnover rate (panel b) and the emissions to the atmosphere in 2030 (panel e) for all scenarios are higher

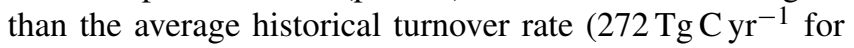
DOM). The forest living biomass and DOM stocks actually increase from 2013 to 2030 under all harvest scenarios because the average age of forests continues to increase even under the higher harvest scenario (see Table S1).

Further losses of $\mathrm{C}$ (panel a) are due to fires (on average, about $1 \mathrm{Tg} \mathrm{Cyr}^{-1}$ for all our scenarios, i.e., about $0.3 \%$ of the total NPP in 2030) and deforestation (about $11 \mathrm{Tg} \mathrm{C} \mathrm{yr}^{-1}$, i.e., $1.7 \%$ of the total NPP in 2030).

The total amount of harvest from the FM area (panel c) varies among the harvest scenarios and equals (in 2030) 108, 128 and $88 \mathrm{Tg} \mathrm{Cyr}^{-1}$ for the constant, increasing and decreasing harvest scenarios, respectively.

Harvests are reported as FW and IRW (panel d). Using the approach of the 2013 IPCC KP LULUCF supplement (Hiraishi et al., 2014), we estimated a direct emission of $\mathrm{C}$ from the FW harvest equal to 26,29 and $20 \mathrm{Tg} \mathrm{C} \mathrm{yr}^{-1}$ for the constant, increasing and decreasing harvest scenarios, respectively. These emissions represent about $4 \%$ of the total NPP. The $\mathrm{C}$ transferred to IRW can be further partitioned into the amount of $\mathrm{C}$ stocked as HWP and the amount released to the atmosphere due to the decay of these products (Hiraishi et al., 2014). The $C$ stock increase in the HWP pool under different future harvest scenarios is reported on the positive $y$ axis of Fig. 3 (panel d). The IRW emissions vary in proportion to the different harvest rates, and represent about $11 \%$ of the

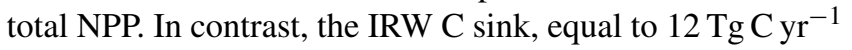
for the historical period, decreases when assuming constant

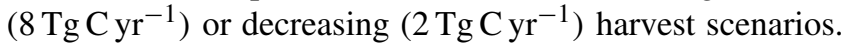
When we assume an increasing harvest, the HWP $\mathrm{C}$ sink in 2030 increases slightly from 12 to $13 \mathrm{Tg} \mathrm{C} \mathrm{yr}^{-1}$.

Subtracting the emissions due to the natural turnover rate from the initial NPP (panel e), natural disturbances and deforestation (panel a) and fellings (panel d), we can estimate the final $\mathrm{C}$ sink of (i) the FM area (including the effect of deforestation), (ii) the HWP pool (stored outside the forest), 


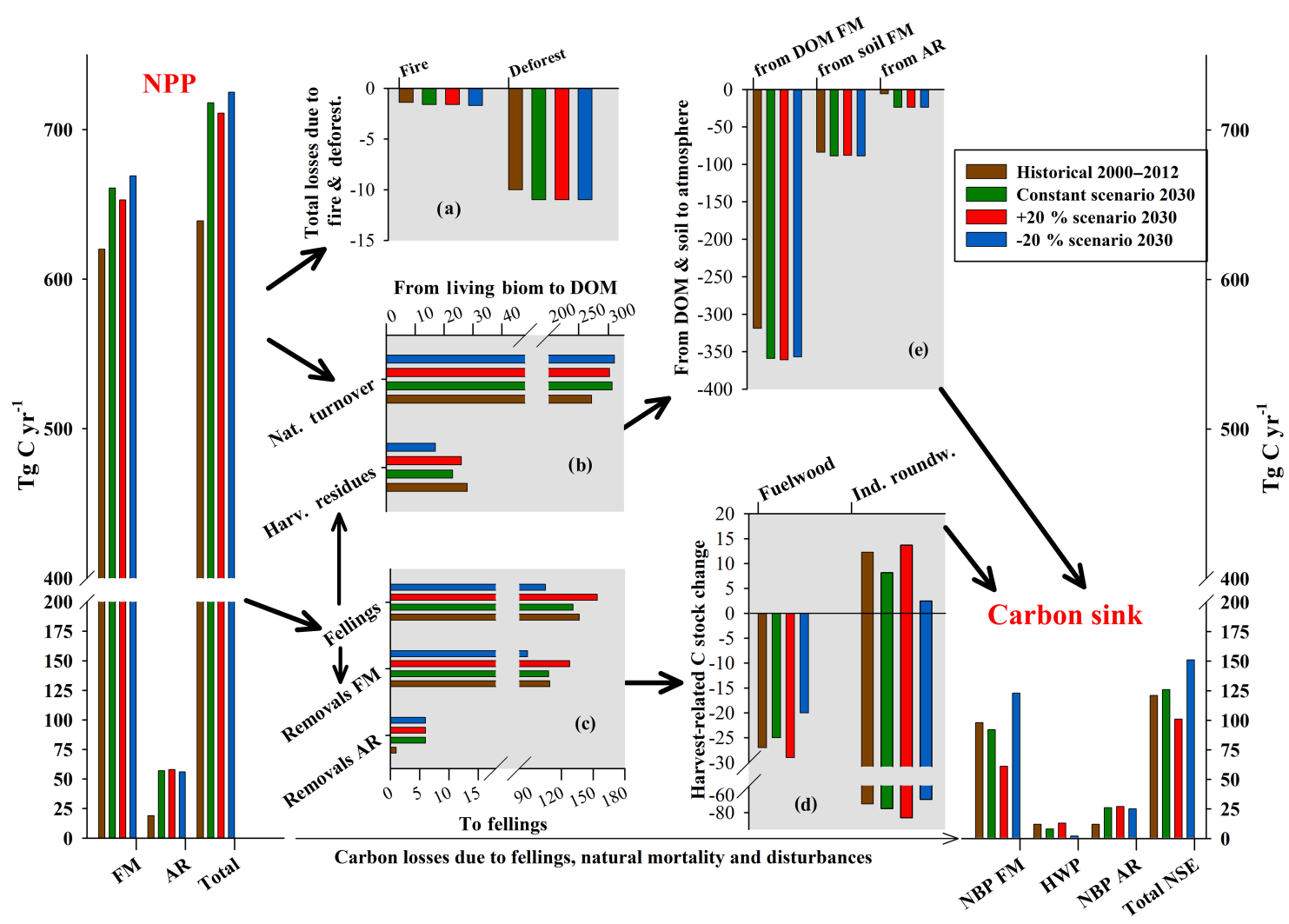

Figure 3. C fluxes for the scenarios of (i) the historical period (average values 2000-2012), (ii) the constant scenario (i.e., constant harvest and AR rate), (iii) the increasing scenario (i.e., increase of $+20 \%$ in harvest and AR rate compared to the average historical harvest and $\mathrm{AR}$ rate) and (iv) the decreasing scenario (i.e., increase of $-20 \%$ in harvest and AR rate compared to the average historical harvest and AR

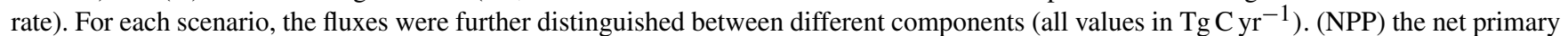
production contributed by the FM area (including deforestation), AR, and total (FM+ AR) is shown. Panel (a) shows the total loss due to natural disturbances and deforestation (i.e., direct emissions to the atmosphere). Panel (b) shows the fluxes of $\mathrm{C}$ from the living biomass to DOM pools (i.e., internal fluxes for the forest ecosystem), further distinguished between fluxes due to self-thinnings and to fellings (i.e., the harvest residues, equal to the difference between fellings and harvest removals). Panel (c) shows the total fluxes of $\mathrm{C}$ due to fellings and the harvest $\mathrm{C}$ removals provided by the FM area and by different AR scenarios. (d) This last flux moves from the forest ecosystem to HWP and may be further distinguished between fuelwood (FW; with a direct emission to the atmosphere, reported with negative values) and industrial roundwood removals (IRW), with negative values referring to the $\mathrm{C}$ emissions to the atmosphere (due to the decay rate of IRW products and industrial losses) and positive values referring to the HWP C sink, estimated by Pilli et al. (2015a). Panel (e) shows the total C emissions from DOM and soil pools to the atmosphere (for the FM area) and from the afforested area (AR; including both DOM and soil). Carbon sink refers to the final C sink, equal to the NPP minus the emissions reported in (a), (d) and (e), further distinguishes between FM area, HWP (i.e., IRW removals), AR and total. Positive values refer to an input of $\mathrm{C}$ to the forest sector (e.g., NPP) or internal fluxes (e.g., from living biomass to DOM), negative values refer to $\mathrm{C}$ losses from the forest sector to the atmosphere (e.g., from DOM and soil to the atmosphere).

(iii) the AR that occurred from 1990 to 2030 and (iv) the total forest sector sink. The $\mathrm{C}$ sink of the FM area (excluding HWP) varies from $98 \mathrm{Tg} \mathrm{Cyr}^{-1}$ for the historical period, to

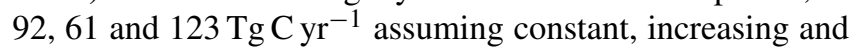
decreasing harvest scenarios. This means that, even maintaining a constant harvest rate from 2013 to 2030, the final NBP of forests existing in 1990 decreases by $6 \%$ in 2030 , compared with the historical period. Increasing the harvest demand by $20 \%$, the NBP decreases by $37 \%$ in 2030, but in all cases the NBP estimates a $C$ sink. Only when the harvest demand decreases, will the NBP increase by $25 \%$. The declining $\mathrm{C}$ sink estimated in the constant harvest scenario is the result of an increasing NPP $(+7 \%$, if compared with the historical period; see Table S1 for details), combined, but with an opposite effect, with an increasing natural turnover and consequent emissions from DOM pools to the atmosphere $(+13 \%)$. This confirms an age-related decline in the productivity of the European forests (Zaehle et al., 2006), and it is consistent with the results from other studies in the literature, suggesting some signs of $\mathrm{C}$ sink saturation in existing European forest (Nabuurs et al., 2013).

Overall, for the historical period, the NBP of the FM area equals $16 \%$ of the NPP (i.e., the input to the forests). This means that about $84 \%$ of the NPP is lost due to natural 
Table 3. Assumptions and main parameters for the model scenarios, compared with figures from Luyssaert et al. (2010) and Karjalainen et al. (2003). FM: forest management area, i.e., area of the existing forests in 1990. AR: afforestation and reforestation that has occurred since 1990.

\begin{tabular}{|c|c|c|c|c|}
\hline $\begin{array}{l}\text { Comparison } \\
\text { between }\end{array}$ & & $\begin{array}{r}\mathrm{CBM} \\
\left(\mathrm{TgC} \mathrm{yr}^{-1}\right)\end{array}$ & $\begin{array}{l}\text { Luyssaert }^{\mathrm{a}} \\
\left(\mathrm{TgC} \mathrm{yr}^{-1}\right)\end{array}$ & $\begin{array}{c}\text { Karjalainen }^{\mathrm{b}} \\
\left(\mathrm{TgC} \mathrm{yr}^{-1}\right)\end{array}$ \\
\hline \multirow{2}{*}{ NPP } & FM & 620 & $520 \pm 75$ & 409 \\
\hline & $\mathrm{AR}$ & 19 & - & - \\
\hline \multirow{2}{*}{$R_{\mathrm{h}}$} & FM & 403 & $287-527$ & 245 \\
\hline & $\mathrm{AR}$ & 6 & - & - \\
\hline Fellings & & 138 & $92 \pm 16$ & 79.5 \\
\hline HWP & & 12 & $5 \pm 3$ & - \\
\hline NBP FM (with HWP) & Tot & 110 & 109 & - \\
\hline
\end{tabular}

and human activities. In 2030, the proportion of NBP in NPP varies considerably: from $9 \%$ for the increasing harvest scenario to $18 \%$ for the decreasing harvest scenario. Since a fraction of the NPP is still stocked in the HWP products, adding this amount to the FM NBP, we can estimate the total $\mathrm{C}$ sink, i.e., the NSE. In this case, the NSE increases to $110 \mathrm{Tg} \mathrm{Cyr}^{-1}$ (i.e., about $18 \%$ of the NPP) for the historical period 2000-2012. This value is considerably higher than the NSE reported by Karjalainen et al. (2003), equal to $87 \mathrm{Tg} \mathrm{Cyr}^{-1}$, but for a lower area (128 compared to $138 \mathrm{Mha}$ ) and a slightly different period (1995-2000). In 2030 , the NSE varies from 100 to 74 and $126 \mathrm{Tg} \mathrm{C} \mathrm{yr}^{-1}$ assuming constant, increasing and decreasing harvest scenarios, respectively (excluding AR). Excluding the substitution benefits and avoided emissions from the use of harvested wood products, this means that (Lemprière et al., 2013; Kurz et al., 2016, and Smyth et al., 2016)

a. with a $20 \%$ harvest reduction, the NSE increases by $15 \%$ compared to the historical period, but the ratio between NSE and NPP remains the same (i.e., the efficiency of the system, equal to about $18 \%$ ).

b. with a constant harvest, the NSE decreases by $9 \%$ compared to the historical period and the ratio with NPP decreases to $15 \%$.

c. with a $20 \%$ harvest increase, the NSE decreases by $32 \%$ compared to the historical period and the ratio with NPP decreases to $11 \%$.

FW varies proportionally to the harvest scenarios, according to the historical data 2000-2012. Therefore, reducing the harvest by $20 \%$ will decrease the energy potential of the FW proportionally, and, vice versa, increasing the harvest by $20 \%$ will increase the energy potential of the FW.

Several studies suggest a significant increase in harvest removals at the EU level for the next decades, mainly due to increasing wood demand for renewable energy production, i.e., the FW demand (Mantau et al., 2010; UN, UNECE, FAO, 2011; EC, 2013). The EU Reference Scenario 2016 (EC, 2016) anticipates a harvest increase of $9 \%$ in 2030 compared to 2005 , with the share of wood removed for energy production increasing from $18 \%$ in 2005 to $28 \%$ in 2030 . According to the same study, because of aging managed forests, this would result in a $30 \%$ decline in the forest C sink in 2030, compared to 2005 . In our study, increasing the harvest by $20 \%$ resulted in a slightly larger reduction of the $\mathrm{C}$ sink, equal to about $38 \%$. Since, in the increased harvest scenario, the HWP C sink equals $13 \mathrm{Tg} \mathrm{C} \mathrm{yr}^{-1}$, reducing the share of IRW and further increasing the FW production would also further reduce the total $\mathrm{C}$ sink.

The average annual NBP on AR lands from 1990 to 2012 is equal to $12 \mathrm{Tg} \mathrm{Cyr}^{-1}$, i.e., about $62 \%$ of the AR NPP. Assuming different afforestation rates from 2012 to 2030, the final NBP in 2030 is equal to 26,27 and $25 \mathrm{Tg} \mathrm{C} \mathrm{yr}^{-1}$, with a constant, increasing and decreasing AR rates, respectively (Table 3). Compared with the historical period, the ratio between NPP and NBP considerably decreases (about $-46 \%$ ) because the potential amount of harvest on AR lands increases from $1 \mathrm{TgC}^{-1}$ for the historical period to about $6 \mathrm{TgC} \mathrm{yr}^{-1}$ in 2030 for all three AR scenarios. While the amount of wood available for harvest until 2012 is negligible (because of the young age of the new forests that have been established since 1990), in 2030 the potential amount of harvest from AR increases, but even then it can only provide less than $6 \%$ of the total EU harvest. In our study, we assumed that this amount was mainly used as FW, i.e., the $\mathrm{C}$ was immediately oxidized.

A further potential amount of harvest, eventually used as FW or IRW, can be provided by the biomass removed from deforested areas, equal on average to about $5 \mathrm{Tg} \mathrm{C} \mathrm{yr}^{-1}$ for the historical period. Due to the lack of detailed information on this use, this amount, equal to about $20 \mathrm{M} \mathrm{m}^{3} \mathrm{yr}^{-1}$ (i.e., about $4 \%$ of the average amount of harvest from 2000 to 
2012), was quantified but not accounted for in the sum of the total roundwood removals and included in the total emissions due to deforestation (see Figs. 2 and S1). This simplified assumption is consistent with the 2013 IPCC KP LULUCF supplement (Hiraishi et al., 2014), which suggests assuming an instantaneous oxidation of the harvest originating from deforestation. In contrast, when assuming that this amount is used as FW or IRW, we should reduce the amount of living biomass removed through other management practices (see Fig. S1e, f, g, arrows). This would slightly increase the living biomass C stock (see Table S1: from 7228 to $7233 \mathrm{Tg} \mathrm{C}$, i.e., $+0.07 \% \mathrm{yr}^{-1}$ ) and, as a consequence, the NBP of the FM area, but it would not affect the direct emissions due to FW and to the decay process affecting IRW since the absolute amount of FW and IRW would not change.

Adding to the previous estimates of the $\mathrm{C}$ sink related to AR, the total NSE of the forest system in 2030 is equal to 126, 101 and $151 \mathrm{TgC}^{-1}$, assuming constant (harvest and AR rate), increasing and decreasing scenarios (see Table S1). Compared with the historical period (with a total NSE equal to $\left.122 \mathrm{Tg} \mathrm{C} \mathrm{yr}^{-1}\right)$, these values are slightly higher $(+3 \%)$, lower $(-17 \%)$ and higher $(+23 \%)$ for the constant, increasing and decreasing harvest and AR scenarios, respectively. Looking at the constant harvest and AR scenarios, these results suggest that the decreasing $\mathrm{C}$ sink detected in the FM area is partly compensated for by the increasing $\mathrm{C}$ sink in the afforested area. These results are based on the assumption that the highest harvest demand is combined with an increasing AR rate, and vice versa. Different combinations of harvest and AR rate may also be possible (see Table 4). However, excluding the FW energy potential, the maximum $\mathrm{C}$ sink is always linked to a reduction of the amount of harvest provided by FM and the minimum $\mathrm{C}$ sink in an increasing harvest scenario. Of course, different assumptions about the share of FW and IRW and a detailed analysis of the FW mitigation potential and of the substitution of other materials with wood products (Sathre and O'Connor, 2010; Lemprière et al., 2013; Smyth et al., 2014, 2016; Kurz et al., 2016), not considered by our study, may yield different results.

\subsection{Carbon balance at country level}

Figure 4 shows, for each country, the average forest ecosystem balance (i.e., the difference between the NPP and $R_{\mathrm{h}}$, harvest and natural disturbances) estimated by CBM for the FM area, for the historical period 2000-2012. The NPP (represented by the green background in Fig. 4) ranges from $2.7 \mathrm{MgCha}^{-1} \mathrm{yr}^{-1}$ for Finland to $9.4 \mathrm{MgCha}^{-1} \mathrm{yr}^{-1}$ for Ireland; the $\mathrm{EU}$ average is $4.5 \mathrm{MgCha}^{-1} \mathrm{yr}^{-1}$. The lower values estimated for Finland and Spain $\left(3.1 \mathrm{MgC} \mathrm{ha}^{-1} \mathrm{yr}^{-1}\right)$ are probably due to specific climatic constraints, which limit the growing season in northern Europe and in the Mediterranean area (Jarvis and Linder, 2000; Kramer et al., 2000). For Ireland, the high estimated NPP is probably due to the fa- vorable climate as well as the use of intensive silviculture and fast-growing species, such as Sitka spruce (Ireland, 2014).

The total loss due to natural processes, such as the decomposition of organic matter, fires and human activities (i.e., harvest; orange slice of each external pie in Fig. 4), varies between $-2.2 \mathrm{MgCha}^{-1} \mathrm{yr}^{-1}$ in Finland and $-8.2 \mathrm{MgCha}^{-1} \mathrm{yr}^{-1}$ in Ireland. The EU average is $-3.8 \mathrm{Mg} \mathrm{Cha}^{-1} \mathrm{yr}^{-1}$. As expected, these losses vary proportionally to the absolute NPP value, and on average the total loss amounts to about $83 \%$ of the NPP. The highest proportion of losses was estimated for Belgium ( $>95 \%$ of the NPP) and the lowest for the UK $(<70 \%$ of the NPP).

The average NBP (white internal pie in Fig. 4) is equal to the difference between the average NPP minus the losses due to respiration $\left(R_{\mathrm{h}}\right)$, harvest $(\mathrm{H})$ and disturbances $(\mathrm{D})$ and varies between $0.1 \mathrm{MgCha}^{-1} \mathrm{yr}^{-1}$ estimated for Belgium and $2.4 \mathrm{Mg} \mathrm{Cha}^{-1} \mathrm{yr}^{-1}$ for the UK. Adding the HWP net sink (also highlighted by the external orange pies in Fig. 4) to the NBP, we can estimate the NSE (labels in Fig. 4). This amount varies between $0.1 \mathrm{MgCha}^{-1} \mathrm{yr}^{-1}$ in Belgium and 2.7 $\mathrm{MgC} \mathrm{ha}^{-1} \mathrm{yr}^{-1}$ in the UK.

Since forest losses are due to the combined effect of natural processes and harvest and they directly affect the final NEP, a more detailed analysis of these parameters may provide useful information.

In Fig. 5 we distinguished the relative amount of $\mathrm{C}$ loss due to nine different processes, including natural (i.e., fires and release of $\mathrm{C}$ due to the decomposition of DOM and soil pools) and human factors (i.e., harvest activities), and we estimated the percentage loss of the total NPP due to each process. The largest release of $\mathrm{C}$ to the atmosphere from the forest ecosystem is due to the natural decomposition of dead wood and litter pools (i.e., DOM $\rightarrow$ atmosphere). In all countries, this covers at least $37 \%$ of total loss, while at the EU level it equals $51 \%$ of total NPP.

The second factor contributing to the total absolute amount of loss is generally represented by human activities, i.e., the use of the merchantable wood components as industrial roundwood. Unlike the previous factor, the relative contribution of this factor varies considerably among countries. In some cases, this may represent more than $20 \%$ of the total NPP (e.g., Belgium), but in other countries this share may be less than $3 \%$ (i.e., Greece and Italy). At the EU level, merchantable wood use represents about $12 \%$ of total NPP.

Releases of $\mathrm{C}$ from soil to the atmosphere represent the third factor contributing to the total loss (on average $13 \%$ of the total NPP). Of course, due to the lack of data, and similarly to other soil models (UN, UNECE, FAO, 2011), the results provided by CBM may be influenced by uncertainty in the model initialization that may directly affect the estimate of the C stock change on this pool (Kurz et al., 2009; Pilli et al., 2013). The carbon balance at the country level, in particular for soil and DOM, is also affected by local climatic conditions. In our modeling framework, we linked the forest area to specific CLUs, associated with values of mean annual 
Table 4. Total C sink estimated by our study for the historical period (average 2000-2012) and for 2030 resulting from combining (i) different harvest scenarios (constant, +20 and $-20 \%$ in 2030, compared with the historical period) applied to the FM area with (ii) different AR scenarios (constant, +20 and $-20 \%$ in 2030 , compared with the historical period). Bold values highlight other possible scenarios not directly considered by our study. FM: forest management area, i.e., area of the existing forests in 1990. AR: afforestation and reforestation that has occurred since 1990. HWP: harvested wood products.

\begin{tabular}{lrrrrr}
\hline \multicolumn{1}{c}{ C sink $\left(\mathrm{Tg} \mathrm{C} \mathrm{yr}^{-1}\right)$} & \multicolumn{5}{c}{ AR } \\
\cline { 2 - 6 } & & $\begin{array}{r}\text { Historical } \\
(\text { avg 2000-2012) }\end{array}$ & $\begin{array}{r}\text { Constant } \\
(2030)\end{array}$ & $\begin{array}{r}+20 \% \\
(2030)\end{array}$ & $\begin{array}{r}-20 \% \\
(2030)\end{array}$ \\
\hline FM (including HWP) & 12 & 26 & 27 & 25 \\
Historical (avg 2000-2012) & 110 & 122 & & & \\
Constant harvest (2030) & 100 & & 126 & $\mathbf{1 2 7}$ & $\mathbf{1 2 5}$ \\
+20\% harvest (2030) & 74 & & $\mathbf{1 0 0}$ & 101 & $\mathbf{9 9}$ \\
$-20 \%$ harvest (2030) & 126 & & $\mathbf{1 5 2}$ & $\mathbf{1 5 3}$ & 151 \\
\hline
\end{tabular}

temperature and total annual precipitation (the CLU's mean annual temperatures range from -7.5 to $+17.5^{\circ} \mathrm{C}$ ). In CBM the decomposition rate for each DOM pool is modeled using a temperature-dependent decay rate (Kurz et al., 2009), which allowed us to consider the effect of regional climate on decay. Due to the lack of data, we did not differentiate biomass turnover rates by region.

For all EU countries, further losses are due to the use of wood for energy. While the IRW is generally provided by the merchantable wood components (or, in some cases, by salvage logging after storms). Based on our assumptions (see also Fig. S1), the FW may be provided through three different sources of materials: merchantable components (e.g., from coppices or early thinnings), other wood components (mainly branches harvested simultaneously with merchantable wood used as IRW) or standing dead trees (i.e., snags, even as salvage logging after fires). The relative share of these three sources varies considerably among countries but it is generally $<5 \%$. In a few countries, the total loss due to the use of wood for energy exceeds $8 \%$ of the total NPP (e.g., France), but at the EU level equals, on average, $4 \%$.

The total loss due to natural disturbances was only accounted for in 22 countries, while 4 countries do not report natural disturbance events. At the EU level, for the historical period 2000-2012, these represent about $1 \%$ of the total NPP. In some countries, however, this percentage may represent, on average, more than $2 \%$. This is the case for Austria, due to the effect of storms and insect attacks, and Portugal due to fires. Natural disturbances may cause direct losses, due to the biomass and dead organic matter burned by fires (i.e., a direct emission of $\mathrm{C}$ to the atmosphere) or indirect losses from the forest ecosystem, due to the salvage of logging residues, after disturbance events or the decay of biomass that was killed during the natural disturbance and transferred to the DOM pools (Pilli et al., 2016b).

We also report the relative amount of loss due to deforestation on the FM area. At the EU level, deforestation represents less than $2 \%$ of the total NPP and, for the majority of the countries, less than $<1 \%$. In a few cases, however, due to the relative large amount of deforestation compared with the total FM area (based on the KP CRF Tables, 2014), the deforestation losses may be higher than $4 \%$ (France and Luxembourg) and, for the Netherlands, equal to $19 \%$ of the total NPP. This country reports an annual rate of deforestation equal to $2000 \mathrm{ha} \mathrm{yr}^{-1}$ (KP CRF Tables, 2014), i.e., about $6 \%$ of the FM area.

\subsection{Carbon turnover time}

Overall, our study suggests that, in the majority of European countries, the build up of biomass stocks results from woody NPP exceeding losses by harvest and natural disturbances, as highlighted by Ciais et al. (2008). While some estimate biomass carbon stocks as a function of NPP minus removals by harvest, this simplified assumption does not take into account the effect of deforestation and other natural disturbances. Some authors highlighted the long-time historical evolution (about 50 years) of this relationship at the EU level, assuming that the slope of the regression line between carbon stocks and NPP was similar between different countries (Ciais et al., 2008; Luyssaert et al., 2010). However, looking at this relationship at the country level, our study shows some interesting differences. The relation between biomass (y) and NPP $(x)$ can be described by a simple linear model: $y=a+\tau \times x$, where $\tau$ represents the evolution of the dependent variable as a function of the NPP and the time that carbon resides in the forest system, i.e., the turnover time (in years, as described by Carvalhais et al., 2014). Through a statistical analysis, using the $R^{2}$ selection method to identify the model with the largest coefficient of determination for each number of variables considered, we can estimate both $a$ and $\tau$ (and their $\pm 95 \%$ confidence intervals) at country level, considering both the aboveground living biomass and the total standing stock (including living biomass, DOM and soil). Looking at the living biomass (Fig. 6a and b), we can identify at least three groups of countries and turnover times: the largest group includes 20 countries with $\tau$ between 5 and 
Average ecosystem balance 2000-2012

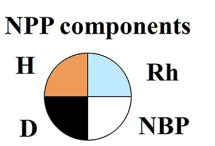

NSE components
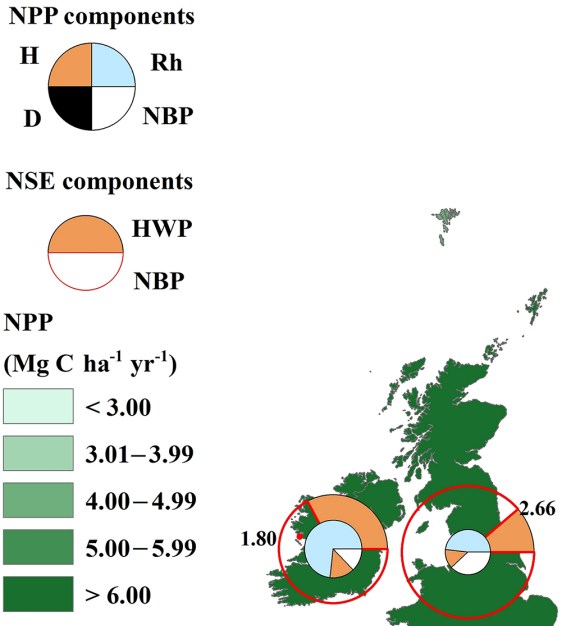

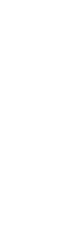

.
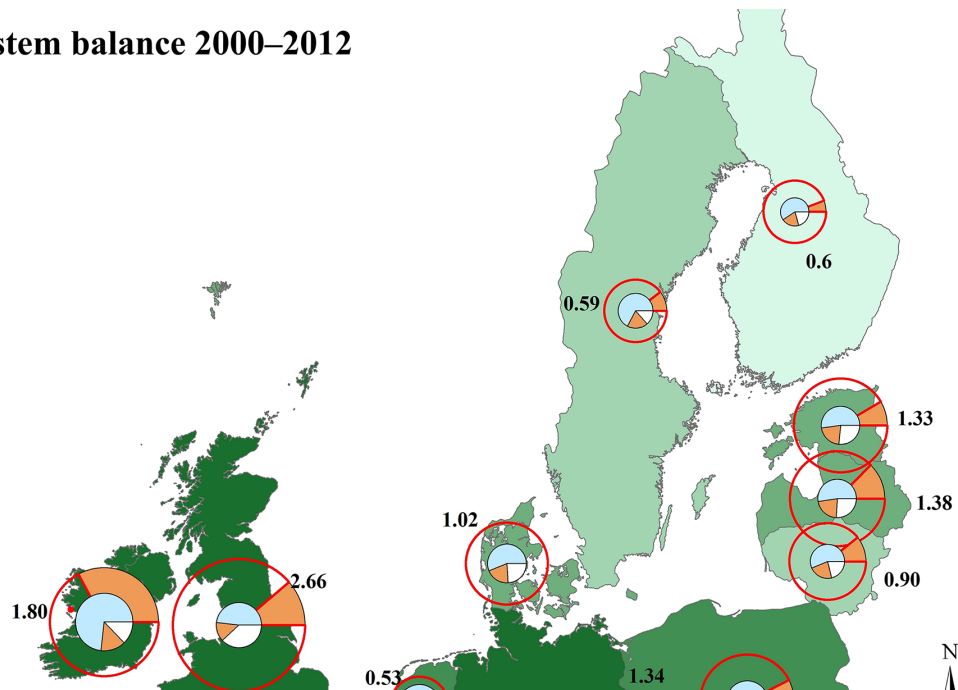

$>6.00$
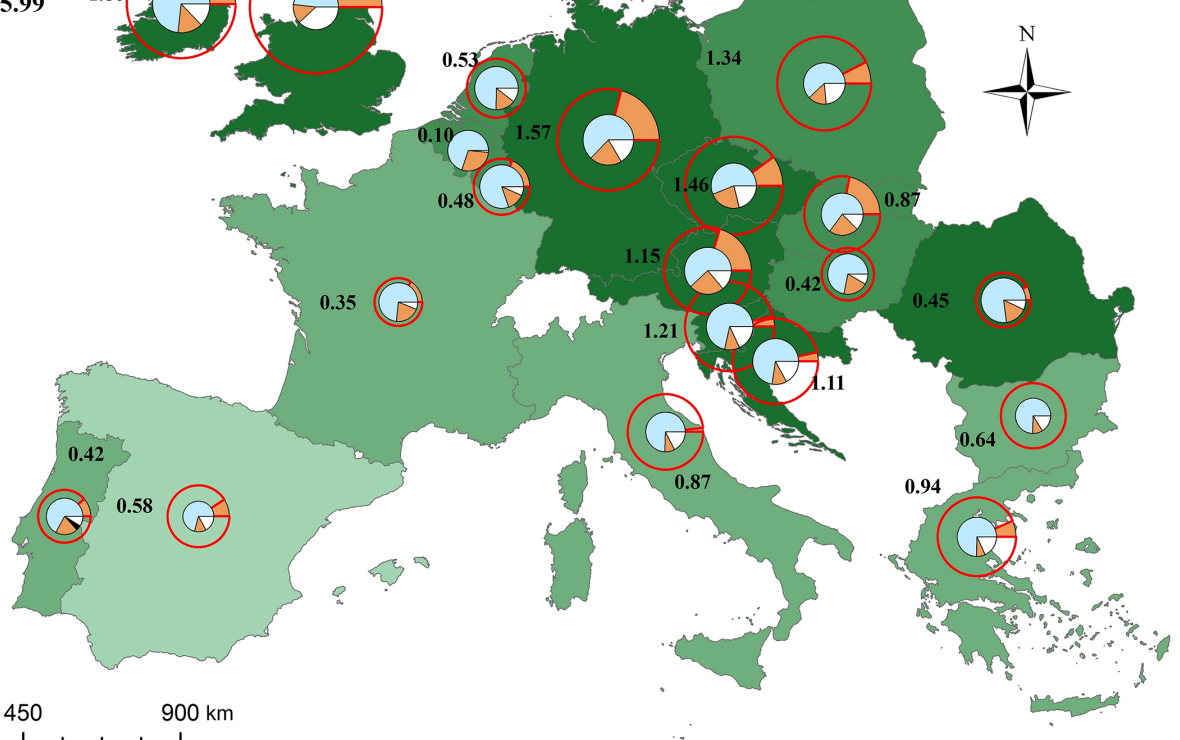

Figure 4. Average ecosystem balance of the FM area for the historical period 2000-2012. For each country the pies of the internal circles highlight the total loss due to respiration $\left(R_{\mathrm{h}}\right)$, harvest $(\mathrm{H})$ and natural disturbances $(\mathrm{D})$, while the average NPP, denoted by the green background (in $\mathrm{MgC} \mathrm{ha}^{-1} \mathrm{yr}^{-1}$ ) is proportional to the radius of the inner circle. The remaining white internal pie, equal to the difference between the NPP and losses, quantifies the net biomass production (NBP). Adding to this amount the HWP net sink, denoted by the external orange pie, we can estimate the net sector exchange (NSE), denoted by the black labels (in $\mathrm{Mg} \mathrm{Cha}^{-1} \mathrm{yr}^{-1}$ ) and proportional to the radius of the external circle.

70 years (for the majority of these countries, $20 \leq \tau \leq 50$, with no statistical difference). All these countries have both an increasing NPP and biomass stock from 2000 to 2012, as well as an increasing turnover time during the same period. For three countries (Italy, Lithuania and the UK) we estimated a turnover rate $>70$, statistically different from the previous group. For Belgium, France and Hungary, the turnover time of $<5$ years (in two cases negative) highlights the countries where we estimated a decreasing NPP (and for Belgium a decreasing biomass against time) and a rather constant turnover time from 2000 to 2012. As expected, the turnover time estimated for the total $\mathrm{C}$ stock is on average $16 \%$ higher than the biomass turnover time (Fig. $6 \mathrm{c}$ and d).
For the Mediterranean countries, where climatic conditions and the effect of fires may reduce the turnover time of the dead wood and litter pool, and for a few other countries (i.e., Denmark and Ireland, due to the young age structure) the turnover time of the total biomass is lower than the turnover time of the living biomass. For 17 out of 25 countries (for Belgium the analysis was not significant), $\tau$ was between 10 and 80 years and in two cases it was again $<0$. Due to the effect of management practices and natural turnover rate (i.e., self-thinnings), the average turnover time estimated for the living biomass, equal to 16.4 years ( \pm 0.6 years), is significantly lower than the average turnover time estimated for the total stock $(25.9 \pm 0.8$ years.). This last value is consistent 


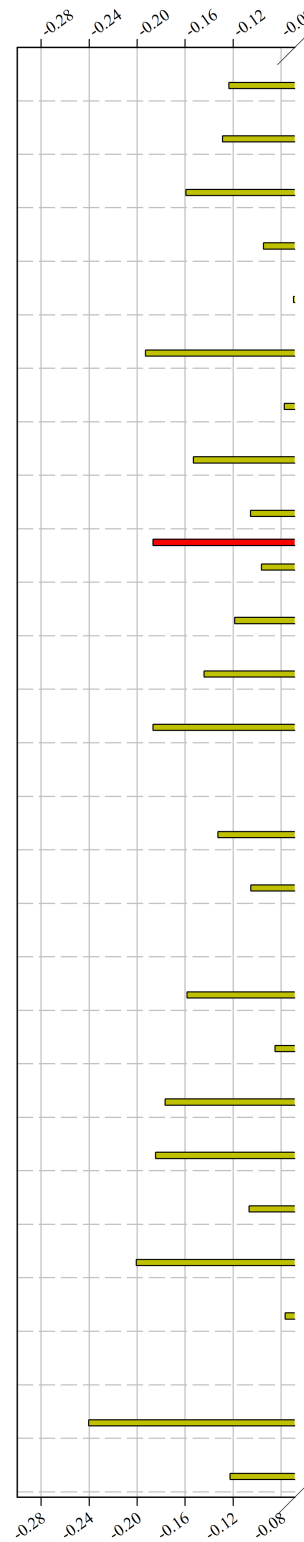

$$
\begin{array}{|l|}
\hline \text { Nat dist --> HWP } \\
\text { Nat dist--> atmosphere } \\
\text { Merch-->IRW } \\
\text { Merch--> FW } \\
\text { OWCs-->FW } \\
\text { DOM-->FW } \\
\text { Deforestation -->atmosphere }
\end{array}
$$

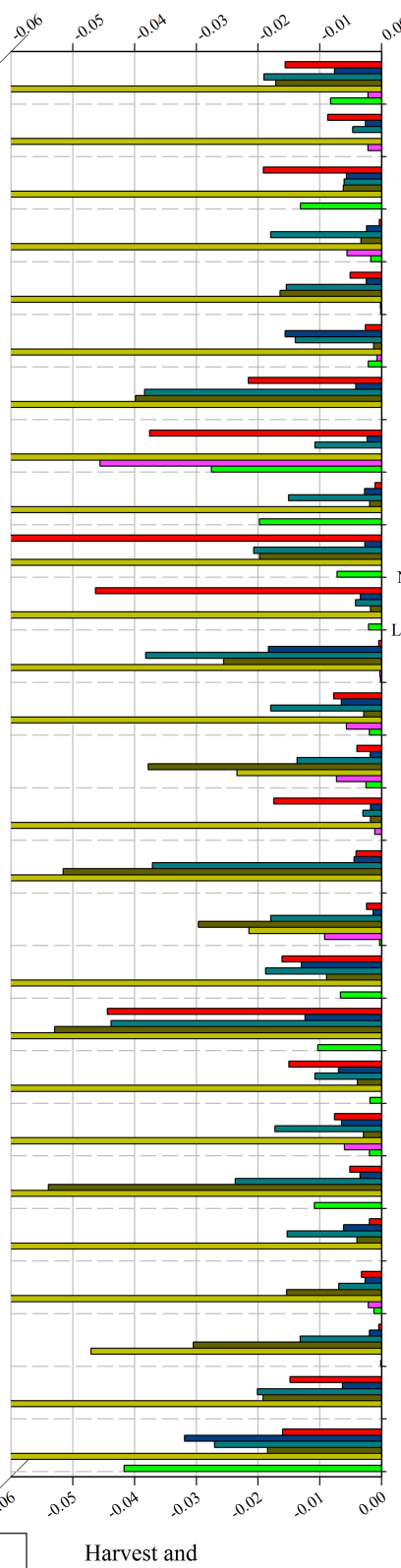

Harvest and

natural disturbances

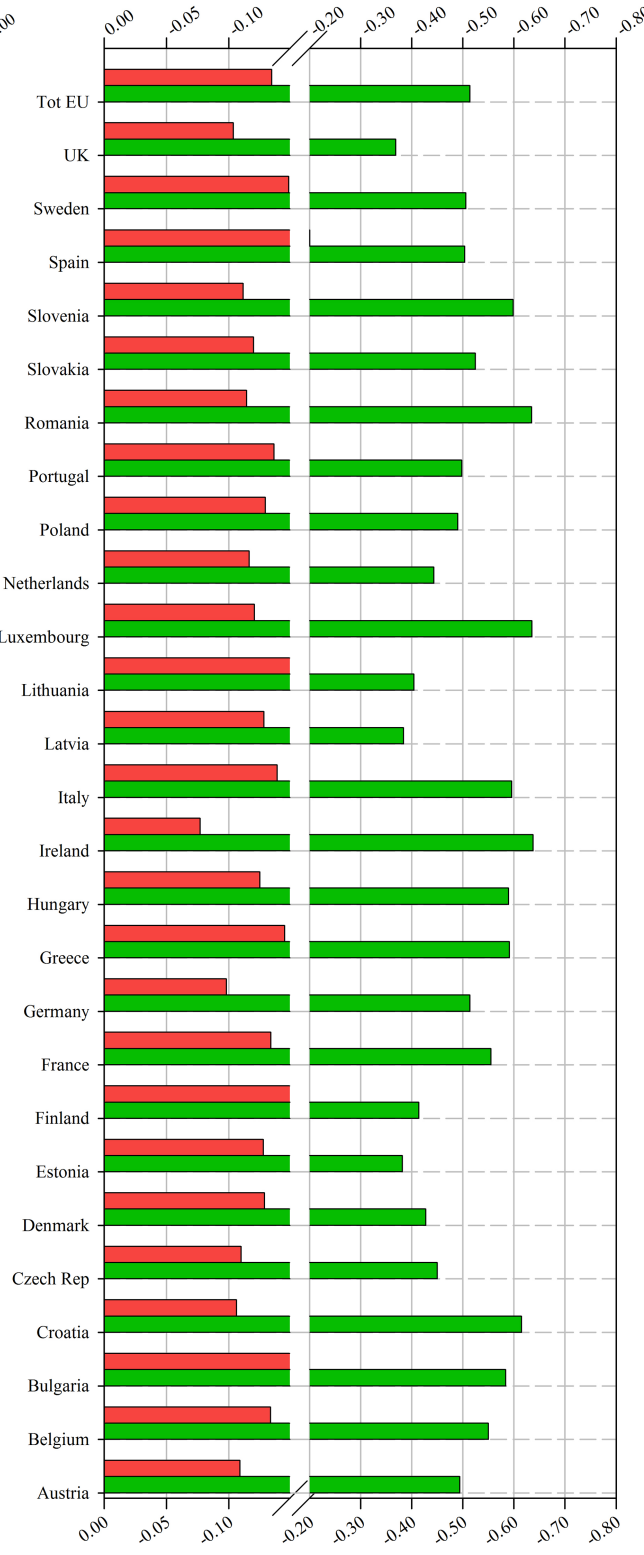

Heterotrophic respiration
Losses as percentage of total NPP

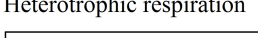

$\square$ DOM ->> atmosphere $\square$ Soil --> atmosphere

Figure 5. Relative amount of $\mathrm{C}$ loss estimated as percentage of the total NPP due to (i) the release of C to the atmosphere for the decomposition of DOM and soil pools, in the right panel, and (ii) natural disturbances (i.e., fires), human activities (harvest) and deforestation, in the left panel. Here we report the relative share of losses due to (i) salvage logging after natural disturbances (Nat dist $\rightarrow$ HWP), (ii) release of $\mathrm{C}$ to the atmosphere due to natural disturbances (Nat dist $\rightarrow$ atmosphere), (iii) merchantable wood used as IRW (Merch $\rightarrow$ IRW), (iv) merchantable wood used as FW (Merch $\rightarrow$ FW), (v) other wood components (i.e., branches, tops) used as FW (OWCs $\rightarrow$ FW), (vi) snags used as $\mathrm{FW}(\mathrm{DOM} \rightarrow \mathrm{FW})$ and (vii) release of $\mathrm{C}$ to the atmosphere due to deforestation (Deforestation $\rightarrow$ atmosphere).

with the overall mean global turnover rate estimated by Carvalhais et al. (2014), equal to $23_{-4}^{+7}$ years. Despite the similarities identified for many countries, we highlighted some sta- tistical difference of the turnover time, suggesting that contrary to the assumptions of Ciais et al. (2008) and Luyssaert et al. (2010), this relationship cannot be assumed constant for 
all European countries. Country-specific forest conditions related to management practices, harvest rates, past age structures and forest composition have varying impacts on the evolution of biomass stock and NPP. Above all, the turnover time estimated for the living biomass seems to be related to the age structure and management practices. Indeed, countries with older forests (such as the UK) and longer rotation lengths applied to clear cuts have the highest $\tau$ (>80 years). In Italy, where clear cuts are often replaced by other silvicultural practices such as thinnings or partial cuts and where a large part of the forest area (mainly coppices) is aging because of a relatively low harvest demand (Pilli et al., 2013), $\tau$ is also over 80 years. An increasing harvest demand, generally combined with a larger use of final cuts and shorter rotation lengths, gradually reduces the turnover time and the average age of the forests. Moreover, exceptional natural disturbances, such as windstorms or fires, may further modify this parameter. Due to the complex interaction between these variables, further analyses are needed.

\subsection{Uncertainties}

Quantifying the overall uncertainty of these estimates is challenging because of the complexity of our analysis. Indeed, the EU estimate is obtained by summing up 26 country-level estimates. For each country, the $\mathrm{C}$ stock of each pool is obtained by multiplying the area of each age class (further distinguished between different FTs and administrative units) with the corresponding volume and by applying a speciesspecific equation to convert the merchantable volume to total aboveground biomass (used as a biomass expansion factor). Therefore, we first consider the uncertainty related to the area, the volume and the equation applied to each FT.

The uncertainty of the area estimates varies among countries. Generally, the information from eastern European countries has a higher uncertainty because of low updating frequency or heterogeneous data sources (e.g., for forest in Romania; V. Blujdea, personal communication, 2016), while the most recent NFIs have lower uncertainty (e.g., $<1 \%$, at the country level, e.g., for Germany or Italy). Considering that the average reference year of the NFIs applied by our analysis is 2003 (see Table 1) we assume that the uncertainty of the area (at the country level) is equal to $2 \%$.

The volume shown in the yield tables applied by CBM derives from a linear interpolation of the volume and increment data reported in each NFI. The uncertainty on these data (when reported) may vary considerably, depending on the relative abundance of each FT (i.e., by the number of plots) but, based on an overview of the NFIs applied to our analysis, we may assume that it is equal to $5 \%$ (in most cases, however, the uncertainty estimate is missing).

Estimating the uncertainty related to the biomass equations applied to each FT is even more challenging. These equations were preliminarily selected, comparing some values available at country level (for 8 out of 26 countries, con- sidering the main FTs and biomass compartments) with the values estimated through specific multinomial models developed by Boudewyn et al. (2007). For each FT, administrative region and biomass compartment, we selected the equation that minimizes the average sum of squares of the differences between the values predicted by the equations and reported in the literature (see Pilli et al., 2013). Therefore, the uncertainty on this component is related to both the uncertainty of the original values reported in the literature and of the multinomial model selected by our analysis. The first uncertainty may vary considerably, depending on the original data source selected for each country. For example, based on NFI data reported for Italy, the standard error of the aboveground biomass estimated at the regional level may vary between less than 3 and more than $100 \%$ (Gasparini and Tabacchi, 2011). For Germany, and for other countries where no detailed information on the biomass was available and this parameter was estimated through allometric equations applied to the original NFI data, the uncertainty may also be higher.

The uncertainty related to the capacity of each model to represent the original values was estimated through the mean percentage difference between the predicted and observed values. This may vary considerably, depending on the forest compartment and the species. For Italy, the mean percentage difference between the total aboveground biomass estimated using the selected stand-level equations and the biomass reported by NFI was $\pm 3.8 \%$ (Pilli et al., 2013). For other countries, we obtained similar results. Where no data were provided by the literature (i.e., for 18 out of 26 countries), we applied the same equations selected for other countries, for similar FTs. Of course, this may further increase the uncertainty of our estimates.

Attributing an overall uncertainty equal to $2 \%\left(U_{\mathrm{A}}\right), 5 \%$ $\left(U_{\mathrm{V}}\right)$ and $3.8 \%\left(U_{\mathrm{B}}\right)$ to the input data on the area, the volume and the expansion of the volume to total living biomass, respectively, and without considering further possible uncertainties (i.e., of the original input data reported by NFIs and of singular FTs and regions) and actual correlations between NFI measured variables, the overall uncertainty on the living biomass stock may be estimated as (Penman et al., 2003)

$U=\sqrt{U_{\mathrm{A}}^{2}+U_{\mathrm{V}}^{2}+U_{\mathrm{B}}^{2}}=6.6 \%$.

The estimates of the $\mathrm{C}$ stock change and, indirectly of the fluxes, are affected by additional uncertainties about the amount of harvest and the amount of area affected by natural disturbances. Comparing different data sources such as NFIs or FAOSTAT data, Pilli et al. (2015) highlighted the inconsistencies of harvest statistics and the uncertainties of these data, which may vary considerably among countries. For example, the Italian NFI reports a $13.3 \%$ uncertainty on the amount of harvest, while the German NFI reports a $1.2 \%$ overall uncertainty. This also affects the uncertainty on the net emissions associated with the HWP pool, which also depends on the initialization and on the decay rate for each 


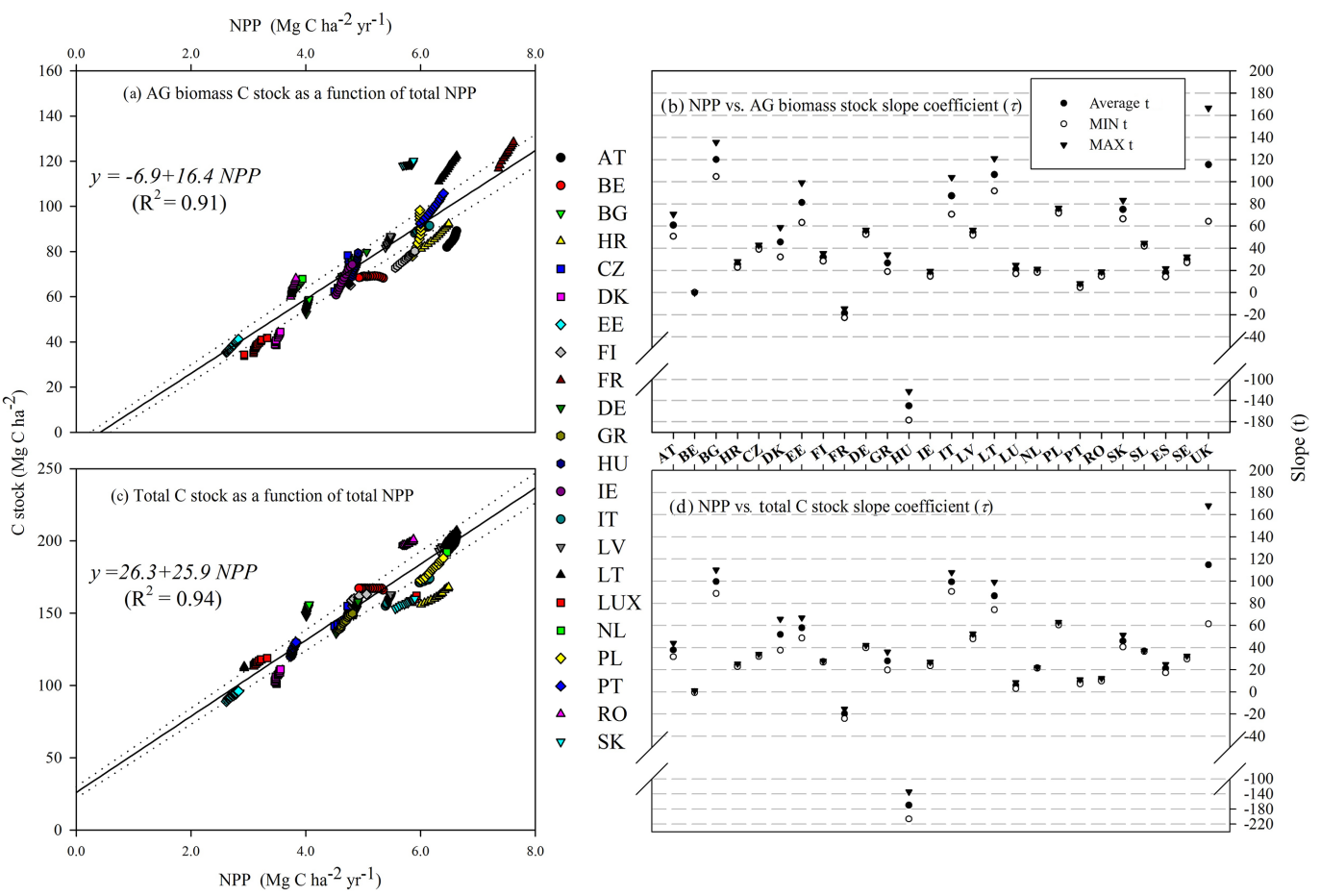

Figure 6. Yearly aboveground living biomass (a) and total (c) $\mathrm{C}$ stock $\left(\mathrm{Mg} \mathrm{Cha}^{-1}\right)$ as a function of total $\mathrm{NPP}\left(\mathrm{Mg} \mathrm{Cha}^{-1} \mathrm{yr}^{-1}\right)$, for the historical period 2000-2012, excluding possible outliers (i.e., years with a distance greater than three interquartile ranges from the medians; SAS Institute Inc., 1990) due to extreme events such as exceptional disturbances. Plots (b) and (d) report, for each country, the slope ( $\tau \pm 95 \%$ confidence interval) of the linear regression model $(y=a+\tau x)$ applied to the previous values for each country (reported on the $x$ axis). In plots (a) and (c), we also highlighted the regression model estimated, at EU level, including all the countries, with the corresponding equation and coefficient of regression $\left(R^{2}\right)$.

wood commodity (i.e., sawn woods, wood-based panels, and paper and paperboard), on the relative fraction of HWP coming from domestic forests and on other sources of uncertainty (described in detail by the 2013 IPCC KP LULUCF supplement; Hiraishi et al., 2014).

Quantifying the uncertainty of the input data for natural disturbances is even more challenging. Due to the lack of data, the uncertainty of land-use change (i.e., afforestation and deforestation), dead organic matter and soil $\mathrm{C}$ pools is even higher. Based on the information reported in the countries' greenhouse gas inventories, for the forest land category, the uncertainty reported by the individual EU member states ranges between 15 and $77 \%$ for the living biomass, between 22 and $113 \%$ for dead organic matter and between 13 and $62 \%$ for mineral soils (Blujdea et al., 2015).

Due to the high number of variables and countries considered by our study, the only way to estimate the overall uncertainty would be through a Monte Carlo approach, as proposed for British Columbia by Metsaranta et al. (2010). However, this would require further data at the country level. Unfortunately, much of this information is often not available or simply does not exist. The yield curves used in CBM are based on field observations, and thus some impacts of environmental changes are represented in the model. However, many of these curves are based on plot measurements over the past decades, and we therefore cannot make any assumptions about how representative the existing yield curves will be for future (2030) environmental conditions. Since CBM does not account for changes in climate, $\mathrm{CO}_{2}$ concentration, $\mathrm{N}$ deposition etc., there is an additional source of uncertainty in the projections due to missing representation of processes that may lead to an increasing or decreasing trend in NPP and $R_{\mathrm{h}}$, depending on the initial climatic conditions (Smith et al., 2016; Kurz et al., 2013).

Our NPP estimates may be compared with other values reported in the literature. Tupek et al. (2010) report the NPP for $24 \mathrm{EU}$ countries (Greece and Croatia were not considered by that study), based on the estimates provided by four different models, for the period 2000-2005 (see Table S3). Between these models, EFISCEN, i.e., an inventory-based model conceptually similar to CBM (Verkerk et al., 2011), generally estimated a NPP higher than CBM for all countries except for Ireland, Slovenia and Spain. The average NPP estimated by this model is $17 \%$ higher than our estimate but it is also combined with a higher contribution of $R_{\mathrm{h}}$, equal on average to $72 \%$ in EFISCEN compared with $64 \%$ in CBM. ORCHIDEE, a process-oriented model, and BIOME-BGC, a climate-based ecosystem model, generally reported a higher 
NPP than CBM: on average +8 and $+16 \%$, for BIOMEBGC and ORCHIDEE, respectively. JULES, i.e., a processbased surface exchange scheme similar to ORCHIDEE, generally estimated a lower NPP than CBM (on average $-24 \%$ at the EU level). Many reasons, such as the use of different data sources, different assumptions about the forest area, the effect of the main natural disturbances (generally not considered by EFISCEN) and silvicultural practices (generally neglected by climate-based ecosystem models) may explain these differences. Looking at the standard deviation estimated by these data series, however, the average NPP estimated by these models $\left(5.54 \pm 1.19 \mathrm{MgCha}^{-1} \mathrm{yr}^{-1}\right)$ is not statistically different from the average value estimated by CBM $\left(5.15 \pm 1.42 \mathrm{Mg} \mathrm{Cha}^{-1} \mathrm{yr}^{-1}\right)$.

Further studies will focus on a specific assessment of these uncertainties, but, in the meantime, to overcome these limitations, we successfully validated our results at the country (for Lithuania) and regional levels (Pilli et al., 2014a) and against independent data sources (Pilli et al., 2013, 2016a).

\section{Conclusions}

This study provides a comprehensive analysis of the main carbon stocks and fluxes in the European forest sector, including country-level details, accounting for forest land-use change, forest management, carbon storage in HWP and the effects of the main natural disturbances. In comparison to two previous studies based on the same model (Pilli et al., 2016a, b), the present work quantifies in detail the $\mathrm{C}$ fluxes and stocks between the forest pools and the atmosphere, including NPP, NSE and $R_{\mathrm{h}}$, up to 2030 and under different model scenarios. For the historical period (2000-2012 average), we estimated an NPP of $639 \mathrm{Tg} \mathrm{C} \mathrm{yr}^{-1}$ for total EU forests, consistent with estimates from other studies, and a NSE of $122 \mathrm{Tg} \mathrm{Cyr}^{-1}$ (i.e., about $19 \%$ of the NPP) for the whole forest system, including HWP. Compared with the historic period, the NSE in 2030 is similar $(+3 \%)$, lower $(-17 \%)$ and higher $(+23 \%)$ when assuming constant, increasing and decreasing scenarios for both harvest and afforestation rates. In this study we did not quantify the avoided emissions from the use of wood products and fire wood, and changes in NSE may not be indicative of the overall changes in greenhouse gas balance resulting from changes in harvest rates. Increased harvest rates will reduce NSE but provide more wood products that can be used to substitute other emission-intensive materials and fossil fuels.

For the forest area existing in 1990 (i.e., the FM area), we show a decline in the $\mathrm{C}$ sink, assuming a constant harvest scenario, due to increasing releases from decomposition $\left(R_{\mathrm{h}}+13 \%\right)$ as the number of DOM pools increase with increasing biomass stocks. This confirms the results of earlier studies, suggesting some signs of $\mathrm{C}$ sink saturation in European forest biomass (Nabuurs et al. 2013). This result, however, should be combined with further analysis, account- ing for the ongoing environmental changes, which could have impacts on NPP and $R_{\mathrm{h}}$ that are not represented in the inventory-based model used in this analysis (Kurz et al., 2013). The nonproportional effect of different harvest scenarios on the $2030 \mathrm{C}$ sink of the FM area suggests that the overall growth of the European forests is slightly decreasing, and by increasing the harvest demand by $20 \%$, we are approaching the maximum harvest potential of the pre-1990 forest area.

Overall, our study shows that forest management succeeds in capturing, on average, $12 \%$ of NPP, as merchantable wood components, while still allowing ecosystem $\mathrm{C}$ stocks to increase. At the country level, we highlighted some statistical differences, suggesting that the relationship between biomass stock and NPP cannot be assumed constant for all EU countries. Specific forest conditions, such as the harvest rate, the age structure and forest composition, may affect the countryspecific evolution of biomass, dead organic matter and soil stocks.

Modeling the wide variety of forest structures and management practices in EU forest is challenging. Most earlier studies focused on specific aspects, e.g., the impact of different policies (e.g., Böttcher et al., 2012), the effect of climate change and management on even-aged forests (Schelhaas et al., 2015), the biomass potential in relation to ecosystem services (Verkerk et al., 2011; Verkerk et al., 2014) and the effect of natural disturbances (i.e., Seidl et al., 2014). By using a flexible model, which allows the accommodation of a wide variety of management practices, input data requirements and natural disturbance events, we managed to explore the forest $\mathrm{C}$ dynamics under different management scenarios with a consistent approach in 26 different countries.

Along with results provided by other models, the detailed picture of the $\mathrm{C}$ fluxes condensed in this study may represent both a benchmark for similar studies and the basis for broader analyses (e.g., including substitution effects of wood) on the mitigation potential of the EU forest sector.

Data availability. Detailed information on the input data and methodological assumptions can be found in Pilli et al. (2016c, doi:10.2788/01911), with the exception of Bulgaria, Ireland, Poland and Romania, where new input data directly provided by the country were applied (see also Table 1 for details). Further details on data sets used for this study can be obtained via personal communication. The Carbon Budget Model used for this study is freely available for download at http://www.nrcan.gc.ca/forests/ climate-change/carbon-accounting/13107.

\section{The Supplement related to this article is available online at doi:10.5194/bg-14-2387-2017-supplement.}


Author contributions. Roberto Pilli carried out the data analysis, in collaboration with Giacomo Grassi. Werner A. Kurz and Alessandro Cescatti helped in the design of the study and the interpretation of results and together with Roberto Pilli and Giacomo Grassi wrote the paper, in collaboration with Giulia Fiorese. All authors read and approved the final paper.

Competing interests. The authors declare that they have no conflict of interest.

Disclaimer. The views expressed are purely those of the authors and may not in any circumstances be regarded as stating an official position of the European Commission or Natural Resources Canada.

Acknowledgements. This paper was prepared in the context of the contract no. 31502, administrative arrangement 070307/2009/539525/AA/C5 between JRC and DG CLIMA. Further information was collected in the context of the AA 071201/2011/611111/CLIMA.A2. The analysis performed for each country was generally based on publicly available data and on additional information collected at the country level, in collaboration with many colleagues and experts from each country. We especially thank our colleagues, Viorel Blujdea and Tibor Priwitzer, who provided useful comments and suggestions. We also thank all the reviewers and the editor for their critical and constructive comments.

Edited by: C. A. Williams

Reviewed by: R. A. Houghton and two anonymous referees

\section{References}

Alkama, R. and Cescatti, A.: Biophysical climate impacts of recent changes in global forest cover, Science, 351, 600-604, doi:10.1126/science.aac8083, 2016.

Bellassen, V. and Luyssaert, S.: Managing forests in uncertain times, Nature, 506, 153-155, doi:10.1038/506153a, 2014.

Blujdea, V., Abad-Vinas, R., Federici, S., and Grassi, G.: The EU greenhouse gas inventory for LULUCF sector: I. Overview and comparative analysis of methods used by EU member states, Carbon Management, 6, 247-259, doi:10.1080/17583004.2016.1151504, 2015.

Böttcher, H., Verkerk, P. J., Mykola, G., Havlik, P., and Grassi, G.: Projection of the future EU forest $\mathrm{CO}_{2}$ sink as affected by recent bioenergy policies using two advanced forest management models, GCB Bioenergy, 4, 773-783, doi:10.1111/j.17571707.2011.01152.x, 2012.

Boudewyn, P., Song, X., Magnussen, S., and Gillis, M. D.: Modelbased, Volume-to-Biomass Conversion for Forested and Vegetated Land in Canada, Canadian Forest Service, Victoria, Canada, Inf. Rep. BC-X-411, 2007.

Bureau for Forest Management and Geodesy: The National Forest Inventory. Results of Cycle II (2010-2014), Sȩkocin Stary, Poland, 2016.
Carvalhais, N., Forkel, M., Khomik, M., Bellarby, J., Jung, M., Migliavacca, M., Mu, M., Saatachi, S., Santoro, M., Thurner, M., Weber, U., Ahrens, B., Beer, C., Cescatti, A., Randerson, J. T., and Reichstein, M.: Global covariation of carbon turnover times with climate in terrestrial ecosystems, Nature, 514, 213217, doi:10.1038/nature13731, 2014.

Ciais, P., Schelhaas, M. J., Zaehle, S., Piao, S. L., Cescatti, A., Liski, J., Luyssaert, S., Le-Maire, G., Schulze, E.-D., Bouriaud, O., Freibauer, A., Valentini, R., and Nabuurs, G. J.: Carbon accumulation in European forests, Nat. Geosci., 1, 425-492, doi:10.1038/ngeo233, 2008.

European Commission (EC): European Commission: EU Reference scenario 2013, Brussels, Belgium, 2013.

European Commission (EC): EU Reference scenario 2016. Energy, transport and GHG emissions, Trends to 2050, Brussels, Belgium, 2016.

FAOSTAT: http://www.fao.org/faostat/en/\#data/FO (last access: January 2016), 2013.

Gasparini, P. and Tabacchi, G. (Eds.): L'Inventario Nazionale delle Foreste e dei serbatoi forestali di Carbonio - INFC 2005. Secondo inventario forestale nazionale italiano. Metodi e risultati, Ministero delle Politiche Agricole, Alimentari e Forestali, Corpo Forestale dello Stato, Consiglio per la Ricerca e la Sperimentazione in Agricoltura, Unità di Ricerca per il Monitoraggio e la Pianificazione Forestale, Edagricole-Il Sole 24 ore, Milano, 2011.

Ghimire, B., Williams, C. A., Collatz, G. J., and Vanderhoof, M.: Fire-induced carbon emissions and regrowth uptake in western U.S. forests: Documenting variation across forest types, fire severity, and climate regions, J. Geophys. Res., 117, G03036, doi:10.1029/2011JG001935, 2012.

Groen, T., Verkerk, P. J., Böttcher, H., Grassi, G., Cienciala, E., Black, K., Fortin, M., Köthke, M., Lehtonen, A., Nabuurs, G.J., Petrova, L., and Blujdea, V.: What causes differences between national estimates of forest management carbon emissions and removals compared to estimates of large-scale models?, Environ. Sci. Policy, 33, 222-232, doi:10.1016/j.envsci.2013.06.005, 2013.

Hiraishi, T., Krug, T., Tanabe, K., Srivastava, N., Baasansuren, J., Fukuda, M., and Troxler, T. G. (Eds.): Revised Supplementary Methods and Good Practice Guidance Arising from the Kyoto Protocol, 2013, IPCC, Intergovernmental Panel on Climate Change, Institute for Global Environmental Strategies for the Intergovernmental Panel on Climate Change, Switzerland, 2014.

Ireland: National Inventory Report 2014, http://unfccc.int/ national_reports/annex_i_ghg_inventories/national_inventories_ submissions/items/8108.php (last access: March 2015), 2014.

Jarvis, P. G. and Linder, S.: Botany - constraints to growth of boreal forests, Nature, 405, 904-905, doi:10.1038/35016154, 2000.

Karjalainen, T., Pussinen, A., Liski, J., Nabuurs, G.-N., Eggers, T., Lapveteläinen, T., and Kaipainen, T.: Scenario analysis of the impacts of forest management and climate change on the European forest sector carbon budget, Forest Policy Econ., 5, 141155, doi:10.1016/S1389-9341(03)00021-2, 2003.

Kauppi, P. E., Mielikäinen, K., and Kuusela, K.: Biomass and carbon budget of European forests, 1971 to 1990, Science, 70-74, doi:10.1126/science.256.5053.70, 1992.

Kirschbaum, M. U. F., Eamus, D., Gifford, R. M., Roxburgh, S. H., and Sands, P. J.: Definitions of some ecological terms commonly 
used in carbon accounting, Cooperative Research Centre for Carbon Accounting, Canberra, 2001.

Koehl, M., Hildebrandt, R., Olschofsky, K., Koehler, R., Roetzer, T., Mette, T., Pretzsch, H., Koethke, M., Dieter, M., Abiy, M., Makeschin, F., and Kenter, B.: Combating the effects of climatic change on forests by mitigation strategies, Carbon Balance and Management, 5, 8, doi:10.1186/1750-0680-5-8, 2010.

KP CRF Tables: Submission 2014, http://unfccc.int/national_ reports/annex_i_ghg_inventories/national_inventories_ submissions/items/7383.php (last access: June 2014), 2014.

Kramer, K., Leinonen, I., and Loustau, D.: The importance of phenology for the evaluation of impact of climate change on growth of boreal, temperate and Mediterranean forests ecosystems: an overview, Int. J. Biometeorol., 44, 67-75, doi:10.1007/s004840000066, 2000.

Kurz, W. A., Dymond, C. C., White, T. M., Stinson, G., Shaw, C. H., Rampley, G., Smyth, C., Simpson, B. N., Neilson, E., Trofymow, J. A., Metsaranta, J., and Apps, M. J.: CBM-CFS3: A model of carbon-dynamics in forestry and land-use change implementing IPCC standards, Ecol. Model., 220, 480-504, doi:10.1016/j.ecolmodel.2008.10.018, 2009.

Kurz, W. A., Shaw, C. H., Boisvenue, C., Stinson, G., Metsaranta, J., Leckie, D., Dyk, A., Smyth, C., and Neilson, E. T.: Carbon in Canada's boreal forest - A synthesis, Environ. Rev., 21, 260 292, doi:10.1139/er-2013-0041, 2013.

Kurz, W. A., Smyth, C., and Lemprière, T.: Climate change mitigation through forest sector activities: principles, potential and priorities, Unasylva, 246, 67, 61-67, 2016.

Lemprière, T. C., Kurz, W. A., Hogg, E. H., Schmoll, G. J., Rampley, G. J., Yemsanov, D., McKenney, D. W., Gilsenan, R., Beatch, A., Blain, D., Bhatti, J. S., and Krcmar, E.: Canadian boreal forests and climate change mitigation, Environ. Rev., 21, 293 321, doi:10.1139/er-2013-0039, 2013.

Lindner, M., Fitzgerald, J. B., Zimmermann, N. E., Reyer, C., Delzon, S., van der Maaten, E., Schelhaas, M.-J., Lasch, P., Eggers, J., van der Maaten-Theunissen, M., Suckow, F., Psomas, A., Poulter, B., and Hanewinkel, M.: Climate change and European forests: What do we know, what are the uncertainties, and what are the implications for forest management? J. Environ. Manage, 146, 69-83, doi:10.1016/j.jenvman.2014.07.030, 2015.

Liski, J., Karjalainen, T., Pussinen, A., Nabuurs, G.-J., and Kauppi, P.: Trees as carbon sinks and sources in the European Union, Environ. Sci. Policy, 3, 91-97, doi:10.1016/S1462-9011(00)000204, 2000 .

Luyssaert, S., Ciais, P., Piao, S. L., Schulze, E. D., Jung, M., Zaehle, S., Schelhaas, M. J., Reichstein, M., Churkina, G., Papale, D., Abril, G., Beer, C., Grace, J., Loustau, D., Matteucci, G., Magnani, F., Nabuurs, G. J., Verbeeck, H., Sulkava, M., Van Der Werf, G. R., Janssens, I. A., and members of CARBOEUROPEIP Synthesis Team: The European carbon balance. Part 3: forests, Glob. Change Biol., 16, 1429-1450, doi:10.1111/j.13652486.2009.02056.x, 2010.

Mantau, U., Saal, U., Prins, K., Steierer, F., Lindner, M., Verkerk, H., Eggers, J., Leek, N., Oldenburger, J., Asikainen, A., and Anttila, P.: Real potential for changes in growth and use of EU forests, EUwood, Hamburg, 2010.

Metsaranta, J. M., Kurz, W. A., Neilson, E. T., and Stinson, G.: Implications of future disturbance regimes on the carbon balance of Canada's managed forest (2010-2100), Tellus, 62, 719-728, doi:10.1111/j.1600-0889.2010.00487.x, 2010.

Nabuurs, G.-J., Lindner, M., Verkerk, P. J., Gunia, K., Deda, P., Michalak, R., and Grassi, G.: First signs of carbon sink saturation in European forest biomass, Nature Climate Change, 3, 792-796, doi:10.1038/nclimate1853, 2013.

Naudts, K., Chen, Y., McGrath, M., Ryder, J., Valade, A., Otto, J., and Lussayert, S.: Europe's forest management did not mitigate climate warming, Science, 351, 597-600, doi:10.1126/science.aad7270, 2016.

Neumann, M., Zhao, M., Kindermann, G., and Hasenauer, H.: Comparing MODIS Net Primary Production Estimates with Terrestrial National Forest Inventory Data in Austria, Remote Sens., 7, 3878-3906, doi:10.3390/rs70403878, 2015.

Penman, J., Gytarsky, M., Hiraishi, T., Krug, T., Kruger, D., Pipatti, R., Buendia, L., Miwa, K., Ngara, T., Tanabe, K., and Wagner, F. (Eds.): Good Practice Guidance for Land Use, Land-Use Change and Forestry. IPCC, Intergovernmental Panel on Climate Change, Institute for Global Environmental Strategies for the Intergovernmental Panel on Climate Change, Hayama, Kanagawa, Japan, 2003.

Pilli, R.: Calibrating CORINE Land Cover 2000 on forest inventories and climatic data: An example for Italy, Int. J. Appl. Earth Obs., 19, 59-71, doi:10.1016/j.jag.2012.04.016, 2012.

Pilli, R., Grassi, G., Kurz, W. A., Smyth, C. E., and Bluydea, V.: Application of the CBM-CFS3 model to estimate Italy's forest carbon budget, 1995 to 2020, Ecol. Model., 266, 144-171, doi:10.1016/j.ecolmodel.2013.07.007, 2013.

Pilli, R., Grassi, G., and Cescatti, A.: Historical analysis and modeling of the forest carbon dynamics using the Carbon Budget Model: an example for the Trento Province (NE, Italy), Forest, 11, 20-35, doi:10.3832/efor1138-011, 2014a.

Pilli, R., Grassi, G., Moris, J. V., and Kurz, W. A.: Assessing the carbon sink of afforestation with the Carbon Budget Model at the country level: an example for Italy, iForest, 8, 410-421, doi:10.3832/ifor1257-007, 2014b.

Pilli, R., Fiorese, G., and Grassi, G.: EU Mitigation Potential of harvested wood products, Carbon Balance and Management, 10, 6, doi:10.1186/s13021-015-0016-7, 2015.

Pilli, R., Grassi, G., Kurz, W. A., Viñas, R. A., and Guerrero, N.: Modelling forest carbon stock changes as affected by harvest and natural disturbances. I. Comparison with countries' estimates for forest management, Carbon Balance and Management, 11, 5, doi:10.1186/s13021-016-0047-8, 2016 a.

Pilli, R., Grassi, G., Kurz, W. A., Moris, J. V., and Viñas, R. A.: Modelling forest carbon stock changes as affected by harvest and natural disturbances. I, EU-level analysis, Carbon Balance and Management, 11, 20, doi:10.1186/s13021-016-0059-4, $2016 \mathrm{~b}$.

Pilli, R., Fiorese, G., Grassi, G., Abad Viñas, R., Rossi, S., Priwitzer, T., Hiederer, R., Baranzelli, C., Lavalle, C., and Grassi, G.: LULUCF contribution to the 2030 EU climate and energy policy, EUR 28025, Luxembourg, Publication Office of the European Union, doi:10.2788/01911, 2016c.

Rüter, S.: Projections of Net-Emissions from Harvested Wood Products in European Countries, Johann Heinrich von ThünenInstitute (vTI), Work Report of the Institute of Wood Technology and Wood Biology, Hamburg, Report 2011/1, 2011. 
Sallnäs, O.: A Matrix Growth Model of the Swedish Forest, Swedish University of Agricultural Science, Faculty of Forestry, Uppsala, Studia Forestalia Suedica, no. 183, 23 pp., 1990.

Sathre, R. and O'Connor, J.: Meta-analysis of greenhouse gas displacement factors of wood product substitution, Environ. Sci. Policy, 13, 104-114, doi:10.1016/j.envsci.2009.12.005, 2010.

Schelhaas, M. J., Eggers, J., Lindner, M., Nabuurs, G. J., Pussinen, A., Päivinen, R., Schuck, A., Verkerk, P. J., van der Werf, D. C., and Zudin, S.: Model documentation for the European Forest Information Scenario model (EFISCEN 3.1.3), Wageningen, Alterra, Alterra-rapport 1559/EFI Technical Report 26, Joensuu, Finland, 2007.

Schelhaas, M.-J., Nabuurs, G.-J., Hengeveld, G., Reyer, C., Hanewinkel, M., Zimmermann, N., and Cullmann, D.: Alternative forest management strategies to account for climate changeinduced productivity and species suitability changes in Europe, Reg. Environ. Change, 15, 1581-1594, doi:10.1007/s10113-0150788-z, 2015.

Schulze, E. D., Ciais, P., Luyssaert, S., Schrumpf, M., Janssens, I. A., Thiruchittampalam, B., Theoloke, J., Saurat, M., Bringezu, S., Lelieveld, J., Lohila, A., Rebmann, C., Jung, M., Bastviken, D., Abril, G., Grassi, G., Leip, A., Freibauer, A., Kutsch, W., Don, A., Nieschulze, J., Börner, A., Gash, J. H., and Dolman, A. J.: The European carbon balance. Part 4: integration of carbon and trace-gas fluxes, Glob. Change Biol., 16, 1451-1469, doi:10.1111/j.1365-2486.2010.02215.x, 2010.

Seidl, R., Schelhaas, M.-J., Rammer, W., and Verkerk, P. J.: Increasing forest disturbances in Europe and their impact on carbon storage, Nature Climate Change, 4, 806-810, doi:10.1038/NCLIMATE2318, 2014.

Smith, W. K., Reed, S. C., Cleveland, C. C., Ballantyne, A. P., Anderegg, W. R. L., Wieder, W. R., Liu, Y. Y., and Running, S. W.: Large divergence of satellite and Earth system model estimates of global terrestrial $\mathrm{CO}_{2}$ fertilization, Nature Climate Change, 6 , 306-310, doi:10.1038/nclimate2879, 2016.

Smyth, C. E., Stinson, G., Neilson, E., Lemprière, T. C., Hafer, M., Rampley, G. J., and Kurz, W. A.: Quantifying the biophysical climate change mitigation potential of Canada's forest sector, Biogeosciences, 11, 3515-3529, doi:10.5194/bg-11-3515-2014, 2014.

Smyth, C. E., Rampley, G. J., Lemprière, T. C., Schwab, O., and Kurz, W. A.: Estimating product and energy substitution benefits in national-scale mitigation analyses for Canada, Glob. Change Biol. Bioenery, doi:10.1111/gcbb.12389, 2016.
Spiecker, H.: Silvicultural management in maintaining biodiversity and resistance of forests in Europe temperate zone, J. Environ. Manage., 67, 55-65, doi:10.1016/S0301-4797(02)00188-3, 2003.

Trumbore, S., Brando, P., and Hartmann, H.: Forest health and global change, Science, 349, 814-818, doi:10.1126/science.aac6759, 2015.

Ťupek, B., Zanchi, G., Verkerk, G., Churkina, G., Viovy, N., Hughes, J., and Lindner, M.: A comparison of alternative modelling approaches to evaluate the European forest carbon fluxes, Forest Ecol. Manag., 260, 241-251, doi:10.1016/j.foreco.2010.01.045, 2010.

UN, UNECE, FAO: The European Forest Sector Outlook Study II. 2010-2030, United Nations, United Nations Economic Commission for Europe, Food and Agriculture Organization of the United Nations, Geneva, 2011.

Valentini, R., Matteucci, G., Dolman, A. J., Schulze, E. D., Rebmann, C., Moors, E. J., Granier, A., Gross, P., Jensen, N. O., Pilegaard, K., Lindroth, A., Grelle, A., Bernhofer, C., Grunwald, T., Aubinet, M., Ceulemans, R., Kowalski, A. S., Vesala, T., Rannik, Ü., Berbigier, P., Loustau, D., Guomundsson J., Thorgeirsson, H., Ibrom, A., Morgenstern, K., Clement, R., Moncrieff, J., Montagnani, L., Minerbi, S., and Jarvis, P. G.: Respiration as the main determinant of carbon balance in European forests, Nature, 404, 861-865, doi:10.1038/35009084, 2000.

Verkerk, P. J., Antilla, P., Eggers, J., Lindner, M., and Asikainen, A.: The realizable potential supply of woody biomass from forests in the European Union, Forest Ecol. Manag., 261, 2007-2015, doi:10.1016/j.foreco.2011.02.027, 2011.

Verkerk, P. J., Mavsar, R., Giergiczny, M., Lindner, M., Edwards, D., and Schelhaas, M. J.: Assessing impacts of intensified biomass production and biodiversity protection on ecosystem services provided by European forests, Ecosystem Services, 9, 155-165, doi:10.1016/j.ecoser.2014.06.004, 2014.

Zaehle, S., Sitch, S., Prentice, I. C., Liski, J., Cramer, W., Erhard, M., Hickler, T., and Smith, B.: The Importance of AgeRelated Decline in Forest NPP for Modeling Regional Carbon Balances, Ecol. Appl., 16, 1555-1574, doi:10.1890/10510761(2006)016[1555:TIOADI]2.0.CO;2, 2006. 